\title{
Nutritional influences on cognitive function: mechanisms of susceptibility
}

\author{
E. Leigh Gibson ${ }^{1 *}$ and Michael W. Green ${ }^{2}$ \\ ${ }^{1}$ Cancer Research UK Health Behaviour Unit, Department of Epidemiology and Public \\ Health, Royal Free and University College Medical School, University College London, \\ 2-16 Torrington Place, London WC1E 6BT, UK \\ ${ }^{2}$ School of Life and Health Sciences, Aston University, Aston Triangle, \\ Birmingham, B4 7ET, UK
}

The impact of nutritional variation, within populations not overtly malnourished, on cognitive function and arousal is considered. The emphasis is on susceptibility to acute effects of meals and glucose loads, and chronic effects of dieting, on mental performance, and effects of cholesterol and vitamin levels on cognitive impairment. New developments in understanding dietary influences on neurohormonal systems, and their implications for cognition and affect, allow reinterpretation of both earlier and recent findings. Evidence for a detrimental effect of omitting a meal on cognitive performance remains equivocal: from the outset, idiosyncrasy has prevailed. Yet, for young and nutritionally vulnerable children, breakfast is more likely to benefit than hinder performance. For nutrient composition, despite inconsistencies, some cautious predictions can be made. Acutely, carbohydrate-rich-protein-poor meals can be sedating and anxiolytic; by comparison, protein-rich meals may be arousing, improving reaction time but also increasing unfocused vigilance. Fat-rich meals can lead to a decline in alertness, especially where they differ from habitual fat intake. These acute effects may vary with time of day and nutritional status. Chronically, protein-rich diets have been associated with decreased positive and increased negative affect relative to carbohydrate-rich diets. Probable mechanisms include diet-induced changes in monoamine, especially serotoninergic neurotransmitter activity, and functioning of the hypothalamic pituitary adrenal axis. Effects are interpreted in the context of individual traits and susceptibility to challenging, even stressful, tests of performance. Preoccupation with dieting may impair cognition by interfering with working memory capacity, independently of nutritional status. The change in cognitive performance after administration of glucose, and other foods, may depend on the level of sympathetic activation, glucocorticoid secretion, and pancreatic $\beta$-cell function, rather than simple fuelling

\footnotetext{
Abbreviations: CCK, cholecystokinin; IQ, intelligence quotient; LNAA, large neutral amino acids; MFF, Matching Familiar Figure; TRP, tryptophan; TYR, tyrosine; 5-HT, serotonin.

*Corresponding author: Dr E. L. Gibson, fax +44 207813 2848, email l.gibson@ucl.ac.uk
} 
of neural activity. Thus, outcomes can be predicted by vulnerability in coping with stressful challenges, interacting with nutritional history and neuroendocrine status. Functioning of such systems may be susceptible to dietary influences on neural membrane fluidity, and vitamin-dependent cerebrovascular health, with cognitive vulnerability increasing with age.

\title{
Glucose: Cognition: Cortisol: Memory: Stress
}

\begin{abstract}
Introduction
The present review is concerned with interpreting the somewhat inconsistent findings from research into effects of food and nutrients on cognitive function. Can patterns be discerned that allow better prediction of responses to nutritional changes, based on knowledge of individual characteristics? Could research findings in this area be better understood as interactions between affective state and cognitive function? The view is taken that assessment of cognitive function involves challenging, even stressful, tasks, on which performance may both elicit and depend on changes in affective state and stress responses. This conceptualisation allows nutritional effects on cognitive function to be mediated by changes in affect or arousal as well as or instead of direct effects on perception, attention and memory. Furthermore, it is argued that more emphasis should be given to both inter- and intra-individual differences in nutritional, arousal and stress-coping status, since these may reflect variation in susceptibility of neurohormonal systems to nutritional manipulation.
\end{abstract}

\section{Nutritional variation $\mathrm{v}$. malnutrition}

Chronic malnutrition undoubtedly hinders cognitive development and performance (Kretchmer et al. 1996; Dauncey \& Bicknell, 1999). However, the present review is not concerned with that literature, nor with the pharmacological effects of ingested substances such as caffeine or alcohol (Rogers, 1995; Bellisle et al. 1998); instead, we review the evidence that acute variation in nutritional status, such as through omission of a meal or by eating a meal of particular composition, may influence cognitive performance or arousal. The impact of variation in nutritional indicators such as blood glucose or vitamins is also included, where these may be considered as measures of nutritional status among populations not overtly malnourished. The susceptibility of cognitive function to such variation may depend on other factors, such as age and vulnerability to stress.

\section{Impact of meals on mental function and arousal}

\section{'...fits of drowsiness are especially apt to come on after meals' Aristotle (350 BC) \\ 'On Sleep and Sleeplessness' (translated by J. I. Beare)}

The postprandial period has long been associated with a restful, quiescent state (Hutchinson, 1952); indeed, in many cultures, a post-lunch nap or 'siesta' is built into the society's daily rhythm. Conversely, hunger has been associated with activation and arousal, poor attention, irritability and aggression (Carlson, 1916; Laessle et al. 1996; Kleinman et al. 1998). 
So, are we more alert and mentally efficient, or over-aroused, distracted and less efficient, before eating than after? It is well established that sympathoadrenal arousal enhances memory formation (McGaugh, 1989). Yet, although eating might be considered to be the antithesis of a 'flight or fight' state of arousal, it has been recognised for some time that food ingestion causes an acute rise in sympathetic nervous system output, resulting, for instance, in an increase in cardiac activity (Young \& Landsberg, 1977; Vaz et al. 1995; Biston et al. 1996). Thus, eating and arousal are not simple opposites. Indeed, eating a meal, or at least its post-ingestive consequence, is a substantial challenge to the body's homeostasis, and in that sense has been viewed as a stressor (Woods, 1991). However, whereas most stressors are potentially harmful, leading to stress responses designed to avoid or minimise their effects, ingestion and absorption of nutrients are, normally, of benefit, and often essential, to the organism. Nevertheless, the body needs to prepare and react appropriately to this sudden influx of nutrients, if their absorption and use are to be optimal, and minimally disruptive. As our eating habits become established, the brain and body become tuned for rapid and appropriate preparation, based on anticipation of meal composition and after-effects, through early detection of sensory and nutritional properties (Woods \& Strubbe, 1994; Teff, 1996). It is within this context that acute nutritional influences on cognitive function and arousal need to be considered.

First, we address evidence for the importance of meal timing during the day, dealing with studies of overall meal effects, in the context of circadian rhythms. Then we consider the influences of the size and composition of meals, in particular where findings suggest mechanisms of susceptibility.

\section{The importance of meal timing}

In man, as in many other animals, there are circadian rhythms and sleep-wake cycles in arousal and performance, which complicate interpretation of the impact of meals. Why should a 'siesta' be needed after lunch, but not after breakfast or an evening meal? Whereas there are many examples of a decline in feelings of vigour and increases in sleepiness in the hours after a midday meal (Lieberman et al. 1986; Smith \& Kendrick, 1992; Owens et al. 2000), it is often not clear whether this is due to eating a meal or merely the time of day. Folkard \& Monk (1985) concluded that this 'post-lunch dip' in performance or arousal probably has both endogenous and exogenous components; when subjects were isolated from time cues, diurnal deterioration in performance similar to the post-lunch dip was seen, but independently of meal timing.

Self-reported alertness or energy rises to a peak in the late morning or midday, then falls later in the waking day (De Castro, 1987a; Smith, 1992). Circadian changes in alertness have often been linked to changes in core body temperature, considered a correlate of physiological arousal (Folkard \& Monk, 1985; Owens et al. 2000). Yet, in rats at least, there are clear preprandial rises and postprandial falls in core temperature (Woods \& Strubbe, 1994); such meal-dependent changes in body temperature do not appear to have been clearly dissociated from temperature-alertness correlations in human subjects (Christie \& McBrearty, 1979). These circadian considerations are not trivial, as circadian rhythms of major hormonal systems such as the glucocorticoids have been shown to be entrainable by feeding regimens (Dallman et al. 1993).

By contrast to subjective alertness, however, circadian changes in cognitive performance have recently been dissociated from core body temperature (Owens et al. 2000). Perceptualmotor (e.g. reaction time) and other attention-based tasks seem to be performed faster but less accurately later in the day, possibly due to attention becoming less focused as time passes 
(Smith, 1992). The circadian pattern of performance on tasks substantially involving memory depends on the level of memory load imposed, so that tasks with greater load are actually performed best earlier in the day (Folkard \& Monk, 1985; Owens et al. 2000). This may in part reflect an inability of less demanding tasks to overcome sleep inertia (Owens et al. 2000), which can impair performance for 2-4 h after waking (Jewett et al. 1999). Another implication is that the timing of peak performance will depend on how demanding an individual participant finds the task.

Other circadian changes may also be important; for instance, test anxiety levels have been found to be higher in the afternoon (Smith, 1985), while spontaneous (anticipatory) anxiety may be higher in the morning (De Castro, 1987b). Furthermore, neurochemical and hormonal activity and function vary across the day, as well as in response to meals (Van Cauter et al. 1992; De Kloet et al. 1993), as does availability of energy substrates including glucose (Shapiro et al. 1991; Biston et al. 1996; Owens et al. 1996). Therefore, the effects of meals on performance and arousal could be expected to vary over a 24-h period. Thus, evidence for acute effects of meals on particular aspects of performance, for instance, may reflect the circadian context of those meals and tasks, as much as any nutritional impact.

Effects of breakfast in children. Interest in the influence of breakfast on subsequent mental and physical performance remains considerable, especially because of the concern that missing breakfast might impair learning in schoolchildren (Pollitt \& Mathews, 1998). However, evidence in support of this belief is equivocal (Smith et al. 1994b). In an editorial review of the oft-cited Iowa breakfast studies of Tuttle and colleagues in the 1950s (Anonymous, 1957), it was concluded that '...there is a considerable degree of variation between individuals in their physiologic and, no doubt, emotional response to breakfast'. In later studies, some attempts have been made to take into account possible sources of such individual variation. For instance, early on there was some support for the idea that any change from a child's habitual eating patterns would lead to a worsening of performance, irrespective of what is or is not eaten (Richards, 1972). This issue gained further support in later studies of the impact of meal size and composition (see p. 177).

In an influential study of effects of omitting breakfast in thirty-four 9-11-year-old children, individual differences clearly affected the outcome (Pollitt et al. 1981). This study is considered in some detail here, because it was the first of this kind to address possible mechanisms by comparing levels of energy substrates with performance measures, and serves to illustrate some of the complexities of interpretation of results in this area. In this within-subjects design, omitting breakfast produced an increase in errors on four easier problems (fewer choices) in a task of visual discrimination (Matching Familiar Figure (MFF) test), but only in subjects whose intelligence quotient (IQ) was below the median. This suggested that higher-IQ children may have been insufficiently taxed by these problems to be affected by acute fasting. Combining both easy and hard problems, errors were increased in those children in whom omitting breakfast reduced blood glucose level, independently of IQ. Curiously, in the fasting condition only, higher-IQ children with above average absolute glucose levels took longer to respond on the hard items than such children with low glucose levels; response time in lower-IQ children was shorter than for higher-IQ children, and was independent of absolute glucose levels. Errors on the hard items did not differ by IQ or glucose in this analysis. This finding suggests that whatever process is maintaining blood glucose during fasting (see p. 186), the higher the blood glucose level achieved, the less efficient are the higher-IQ children in this MFF task. We will return to this issue of glucoregulation and performance later, when discussing studies in adults that specifically sought to relate blood glucose to performance. However, one potential con- 
founder that needs to be considered is time since awakening, as the earlier risers may have both lower blood glucose and less sleep inertia. Also, given the discussion earlier on circadian changes in peak performance and memory load, another point should be noted here: for an IQdependent memory task, lower-IQ children would be more likely to achieve their peak performance in the morning than would higher-IQ children.

In addition, omitting breakfast actually improved accuracy for the last item on a serial recall memory test (Hagen Central Incidental test), for all the children.

Whilst blood glucose level was not affected on average by missing breakfast, lactate, nonesterified fatty acids and $\beta$-hydroxybutyrate were all elevated when breakfast was omitted (Pollitt et al. 1981). This situation probably results from sympathoadrenal and glucocorticoid stimulation of lipolysis, proteolysis, gluconeogenesis and muscle glycogenolysis, so releasing energy substrates while protecting liver glycogen stores (McMahon et al. 1988). However, it should be noted that these measurements, including glucose, were taken immediately after the cognitive tests, and so do not simply reflect fasting status, but may also be a consequence of stress or arousal during fasting. Pollitt et al. (1981) suggested that the intensity of this physiological response to fasting would be inversely proportional to blood glucose level. However, it is not clear why this should be the case following stress; in fasted and stressed rats, blood glucose only rises when adrenaline is released, and this stress-induced hyperglycaemia is independent of glucocorticoid release (Yamada et al. 1993). If adrenaline release is prevented (by adrenomedullation), blood glucose falls in stressed fasted rats, whereas hyperglycaemia in stressed fed rats is not so dependent on adrenaline (Yamada et al. 1993). Indeed, it is clear that an important mechanism by which adrenaline enhances blood glucose is by inhibition of uptake and disposal of glucose (Sherwin \& Saccà, 1984). Thus, we suggest that lower blood glucose during fasting and after stress may instead reflect a weaker adrenergic response.

If that is the case, then lower adrenergic arousal might contribute to the increased error rate on the MFF task in children whose blood glucose was lower when missing breakfast than with breakfast. During fasting, the increased latency to respond on this task would, on this argument, be associated with a greater adrenergic arousal, specifically in higher-IQ children. Perhaps such arousal interfered with decision making on this task in more thoughtful children, or reflected greater involvement or anxiety; final error rates were unaffected. The fasting-induced increased error rate, on easy MFF items, among lower-IQ children, might reflect an interaction between task engagement and fasting-induced arousal.

In an extension of this design on a further thirty-nine 9-11-year-olds, Pollitt et al. (1983) found more consistent results after statistically controlling for latency to respond (which was again longer in higher-IQ children, and so in part controls for IQ level, and perhaps demand and involvement too). This time, omitting breakfast resulted in significantly lower (post-test) group mean blood glucose, and lower insulin levels (not measured in the first study). Omitting breakfast increased the number of errors on the MFF test (adjusted for response time), irrespective of IQ level. For the hard problems only, children with lower post-test blood glucose and insulin produced more errors, which could reflect a lack of engagement.

Interestingly, omitting breakfast resulted in better recall of the incidental objects in the Hagen Central Incidental test, i.e. those to which the children were not instructed to attend, but which were paired with the target figures. Importantly, this score of attention to irrelevant stimuli is known to correlate positively with increased anxiety (Dusek et al. 1976). Furthermore, this incidental attention score was greater in children with lower post-stress insulin (but not glucose) levels during fasting. This would be compatible with suppression of insulin release by greater arousal or stress in more anxious children.

Further evidence that fasting due to omitting breakfast can have an arousing effect under 
challenge was provided by a study comparing cardiac and cortical evoked potential orienting responses after breakfast or no breakfast in 9-11-year-old children (Conners \& Blouin, 1983). Vigilance errors and performance variability increased over three morning test periods, but to a greater extent when fasting. Likewise, arithmetic was, increasingly over the morning, better with breakfast than without. Like performance, the breakfast-no-breakfast differences in the physiological data increased during the morning, suggesting that breakfast might aid performance by restraining sympathoadrenal reactivity, which was exaggerated when fasted.

When considering possible nutritional mechanisms, it is important to note that beneficial effects of breakfast on performance have been found $3 \mathrm{~h}$ after the meal (Pollitt \& Mathews, 1998), when blood glucose is likely to have returned to pre-meal levels. Nevertheless, Pollitt et al. (1981) argued cogently that young children were likely to be more susceptible to effects of brief fasting than adolescents or adults, due to greater brain metabolic demands relative to liver and muscle glycogen and to gluconeogenic capacity. This argument seems largely to have been overlooked by later workers in this area, but may yet be worth bearing in mind; indeed, uncontrolled individual differences in glycogen stores at the time of participation might explain much of the variation. Pollitt \& Mathews (1998) reviewed evidence suggesting that the beneficial effects of breakfast on mental performance may be greater for children with a history of malnutrition.

This increased nutritional sensitivity of performance in younger children might underlie data from a much larger sample of 595 schoolchildren ranging in age from 11 to 18 (Dickie \& Bender, 1982). There was no consistent evidence for an influence of morning food intake, or its lack, on memory and attention, overall. However, among the younger children only (average age 12.5 years), the mean test scores indicated a tendency for slower speed and less accuracy in subjects omitting breakfast, although no statistical comparison of these group means was reported.

It can be seen that consistent evidence for a beneficial effect of breakfast on cognitive performance remains elusive. In particular, we suggest that individual differences in engagement and task demand will obscure any relationships between breakfast, or breakfast-dependent changes in blood glucose, and mental performance. There remains a need for more tightly controlled studies of the possible effects, and mechanisms of action, of breakfast in large samples of children.

Effects of breakfast in adults. Effects of breakfast, or its omission, on performance are not limited to children, despite the argument that children, especially if poorly nourished, might be most sensitive to short-term fasting. Even so, few studies in adults have simply compared effects of breakfast with its omission on performance. In thirty-three healthy university students, omitting breakfast lengthened the time taken to complete spatial and verbal recall tasks $2 \mathrm{~h}$ later, compared with a group consuming a protein-rich 'milk-shake' (1368 kJ (327 kcal); \% energy as protein, carbohydrate, fat: $23,43,34$, respectively) for breakfast (Benton \& Sargent, 1992). Accuracy did not differ between these groups, so clearly the fasted group was performing less efficiently. Within this group, higher blood glucose predicted faster completion of the spatial memory task. Within the non-fasted group, higher blood glucose predicted fewer errors on this task. Although no measures of mood or arousal were reported, these findings may indicate differences in test-induced sympathoadrenal or adrenocortical arousal across subjects within a group, mediating both hyperglycaemia and increased speed of performance. However, interpretation is limited by uncertainty as to when the glucose was measured, and whether other glucose-performance correlations differed statistically from those mentioned. Furthermore, the milk-shake might have induced effects that would not be apparent after a habitual breakfast.

Two more recent studies in adults (Smith et al. 1994b; 1999a) addressed whether effects of breakfast were specific to memory-based tasks or included tasks assessing sustained attention, 
reaction time, and logical or semantic reasoning. In both studies, mood and performance were measured at 1 and $2 \mathrm{~h}$ after breakfast; pre-breakfast measures were used as covariates.

In line with previous findings, Smith et al. (1994b) found (in students; 8-12/group, two studies) that breakfast improved free recall and recognition of words, whereas attention-based and reaction-time tasks were unaffected. Logical reasoning was slightly impaired $2 \mathrm{~h}$ after breakfast.

The later study (Smith et al. 1999a), inspired by more consistent effects of breakfast on memory tasks than on attention, investigated effects of breakfast specifically on different components of memory in students (thirty-six per group). The only effect of breakfast detected was an improvement in spatial memory. This is a replication of an earlier finding (Benton \& Sargent, 1992); nevertheless, the lack of benefit of breakfast on a task requiring recall of a series of digits is surprising given that other studies found improvements in word list recall tasks (Benton \& Sargent, 1992; Smith et al. 1994b). One possibly important difference between the later study and the previous two was that Smith et al. (1999a) did not provide a standard 'breakfast', but allowed students to choose how much cereal to eat.

Another problem with these studies is that it is difficult to dissociate completely effects of caffeine or its absence from those of breakfast or its omission. Even though Smith et al. (1994b, 1999a) included caffeine and no-caffeine groups, any effects of breakfast or its absence in the no-caffeine group may be confounded by caffeine withdrawal. Indeed, withdrawal would have been the situation at baseline for many subjects irrespective of group. It is also not clear what knowledge or expectations about the design were held by subjects; these could have been further sources of artefacts.

Neither of these studies found any effect of personality type, such as extraversion or neuroticism (see p. 175), although it is not clear whether the samples included sufficient variation in these traits to test such relationships effectively (unstable neurotics may be harder to recruit). Furthermore, such traits may become more influential later in the day (Smith, 1992).

Effects of the midday meal. As mentioned earlier, a quite consistent finding has been a drop in performance after the midday meal, known as the 'post-lunch dip' (Folkard \& Monk, 1985; Smith \& Kendrick, 1992; Owens et al. 2000). It appears that performance on tasks requiring sustained attention are more likely than briefer tasks of selective attention to be attenuated by lunch (Christie \& McBrearty, 1979; Smith \& Miles, 1986b). However, it remains unclear to what extent the 'post-lunch dip' actually depends on eating lunch (Folkard \& Monk, 1985); an underlying rhythm in performance also seems likely to contribute, since vigilance was worse in the early afternoon than late morning, in subjects not eating lunch (Smith \& Miles, 1986a).

An intriguing finding was that subjects' scores on the extraversion and neuroticism scales of the Eysenck Personality Inventory correlated, respectively, positively and negatively with the post-lunch dip in performance (Craig et al. 1981). Thus, stable extraverts were more vulnerable to post-lunch dip. This finding was replicated on a vigilance task by Smith \& Miles (1986a), who in addition found that pre-lunch-post-lunch changes in state anxiety correlated $(r 0.83)$ with pre-lunch-post-lunch differences in vigilance performance. That is, the greater the reduction in anxiety after lunch, the greater the drop in performance. So, it appears that anxious individuals, not calmed by lunch, maintain their level of performance after the meal. Similarly, when subjects were aroused by noise stress, no post-lunch dip in performance was seen, although pre-lunch performance was worse with noise (Smith \& Miles, 1986a). An earlier finding may be of particular importance here: Christie \& McBrearty (1979) found that stable extraverts showed a greater peak and subsequent decline in blood glucose after lunch than neurotic introverts. This greater change in blood glucose was also associated with less 'activated' 
mood and slower cognitive performance. Possible implications of these findings are discussed later (p. 187), when we consider glucoregulation and cognitive performance in more detail.

Between-meal snacks. Kanarek \& Swinney (1990) investigated whether an afternoon snack (1004 kJ (240 kcal) yoghurt or $1213 \mathrm{~kJ}$ (290 kcal) confectionery) would affect cognitive performance (15-60 min later) of male students, if eaten about $3 \mathrm{~h}$ after lunch or after no lunch. A zero energy 'diet' drink was used as a snack 'placebo' (subjects were blind to energy content). Both breakfast and lunch were standardised. Eating the energy-containing snack had a beneficial effect on memory, arithmetic reasoning, and reaction time on a continuous performance task. Reading speed was not affected by snack condition, although, in the second experiment, reading was slower if no lunch was given. The only other effect of lunch was that the snackinduced improvement in arithmetic reasoning in the first experiment did not occur without lunch. These results are impressive in their replicability and statistical significance in a small number of subjects (eighteen in all). However, they are hard to interpret mechanistically. If presence or absence of lunch had little or no impact on the snack effect, direct nutritional effects may not be important. Pre-absorptive psychological or physiological reactions to the sensory properties of the snacks may be involved (effects were seen on the first test 15-25 min after eating the snack) or the influence of expectations could be important. The timing of this snack intervention may be critical, but makes comparison with meal effects difficult. Although the snacks were perhaps eaten rather too late to influence any post-lunch dip (Craig, 1986; Smith \& Kendrick, 1992), it was at a time of day when alertness, energy and memory performance are starting to decline (De Castro, 1987a; Smith, 1992). Moreover, these beneficial effects of afternoon snacks apparently do not occur in the late morning (unpublished data cited in Kanarek \& Swinney, 1990). Perhaps, eating the snack provided sufficient arousing stimulation, irrespective of nutritional consequences, to enhance performance during normal circadian decline.

Effects of evening meals. There are very few data on the effects of evening meals on mood and performance, which probably reflects the greater inconvenience of conducting research later in the day. Even so, given circadian changes in numerous variables that might be implicated in such effects, including mood and performance, as well as physiological variables, it seems likely that differences between evening and earlier meals would occur. When changes in performance after a meal in the middle of a nightshift were compared with after lunch, some differences were found (Smith \& Miles, 1986a); for instance, the midday meal impaired speed and accuracy, whereas only accuracy was impaired during the nightshift. Also, whereas anxious subjects showed resistance to lunch, anxiety level did not affect responses to the nightshift meal.

Smith et al. (1994c) studied the effects of a large evening meal (5·02-6.28 MJ (1200-1500 kcal)), freely chosen from a college refectory, on mood, performance, blood pressure and heart rate, in twenty-four men and twenty-four women. Half the subjects had no meal, and half had caffeine added to decaffeinated coffee. Measures were taken pre-meal and 90 and 180 min after starting eating. We will consider only the meal effects here. At $3 \mathrm{~h}$ after starting eating, pulse rate but not blood pressure was higher after the meal than after no meal. By this time, subjects who omitted the meal felt more feeble and incompetent, while these feelings did not change in fed subjects. Also, after eating, subjects felt more outward-going compared with fasted subjects. However, out of six performance tests, repeated twice, there was little evidence for consistent differences between fed and fasted subjects, which suggests that performance was not clearly related to changes in subjective mood. 


\section{Influence of meal size}

It might at first seem obvious that a large meal would have a different impact from a small meal, but a number of difficulties arise in trying to establish evidence for such a difference. For example, how much bigger should the large meal be, or how small can the small meal be? Should the size comparison be in terms of energy, volume, weight, consumption time, or all of these? When should behavioural outcome measures be taken? For instance, $1 \mathrm{~h}$ after eating, the amount of nutrients absorbed from a small meal may not differ appreciably from that absorbed after a large meal, though the volume of food remaining in the stomach will of course differ. Does the meal differ in size from each subject's habitual meal, and is that important? What form of 'dose-response' pattern would be expected? Does meal size interact with time of day?

Few of these issues have been addressed systematically, as the majority of studies in this area have used meal sizes that were standardised and more or less resembled typical breakfasts or lunches for the subjects concerned, or subjects were allowed to self-select their own meals. Nevertheless, there are some exceptions; for instance, Craig \& Richardson (cited in Craig, 1986) compared the effects of a heavy (about 4.18 MJ (1000 kcal)) and a light (<1.26 MJ (300 kcal)) meal on performance on a letter cancellation task (no further meal details were given). On average relative to pre-lunch performance, more letters were missed after the heavy meal, whereas fewer letters were missed after the light lunch. However, these effects were not apparent in those subjects for whom the experimental meal was of similar size to their habitual lunch.

When the energy content of lunch was varied in increments of $40 \%$ (the middle-sized meal equivalent to one third of energy requirements), only the largest meal affected cognitive performance, with more errors occurring on tests of attention and vigilance $1 \mathrm{~h}$ later (Smith et al. 1991). Meal size did not affect mood, but positive affect (e.g. alertness, interest) declined equally after all meals. In that study, proportions of macronutrients had been kept constant (and typical), but when a lunch with $50 \%$ more energy contained additional fat, performance on such tasks tended to be slower but more accurate (Smith et al. 1994a). Subjects also felt calmer after the high-fat meal. However, those small effects on performance and mood interacted with meal weight, which was independent of fat content in that design.

Two studies have compared large and small breakfasts on performance and mood. In adolescents, a larger breakfast (on average $2653 \pm 996 \mathrm{~kJ}(634 \pm 238 \mathrm{kcal})$ v. $1628 \pm 791 \mathrm{~kJ}(389 \pm$ $189 \mathrm{kcal})$ ) resulted in poorer vigilance but better short-term memory, $3 \mathrm{~h}$ later (Michaud et al. 1991), although there was no evidence of an energy dose-response effect (when intake was grouped by $418 \mathrm{~kJ}$ (100 kcal) steps). Alertness and tranquillity, and post-test blood glucose, were unaffected by size of breakfast. In 10-year-old children, a larger breakfast improved verbal fluency, at least in boys $(2243 \mathrm{~kJ}(536 \mathrm{kcal}) v .711 \mathrm{~kJ}(170 \mathrm{kcal})$ on average), whereas eating very little for breakfast was associated with comparatively worse mood and performance on simple tasks (Wyon et al. 1997). However, the design did not exclude the possibility that underlying motivation could have contributed to both breakfast consumption and task performance.

In an observational study in a residential laboratory, in which energy content of breakfasts and lunches varied, there was little evidence of any relationship between meal size and performance measures (mood was not reported) (Kelly et al. 1994). However, effects may have been obscured by lack of control of nicotine and caffeine consumption in the small number of subjects.

Overall, it appears that meal size can influence performance, but for better or worse depending on the nature of the task. Also, there is likely to be a trade-off between sufficient energy supply and demands on processes of absorption and metabolism and associated neurohormonal systems. Mood does not appear to be particularly sensitive to meal size, unless very 
little is eaten or stress is present; when subjects were stressed by noise, higher energy intake prevented deterioration of mood (Macht, 1996). However, it is difficult to compare the few studies in this area, and, as we shall see, within reasonable limits, composition may be more influential than absolute size.

\section{Meal composition, performance and mood}

\section{Protein v. carbohydrate}

There has been rather more research interest in the effects of meal composition, especially macronutrients, on mood than on cognitive performance (Rogers, 1995). This is largely because of evidence that plasma and brain levels of precursor amino acids for synthesis of monoamine neurotransmitters, strongly implicated in affective disorders, can depend on carbohydrate : protein ratios in the diet (Wurtman et al. 1981). Synthesis of serotonin (5-hydroxytryptamine; 5-HT) depends on dietary availability of the precursor essential amino acid, tryptophan (TRP), due to a lack of saturation of the rate-limiting enzyme, tryptophan hydroxylase (Fernstrom, 1983). An important complication is that TRP competes with several other amino acids, the large neutral primarily branched-chain amino acids (LNAA), for the same transport system from blood to brain. If the protein content of a meal is sufficiently low, such as $5 \%$ (or less) total energy as protein, then relatively few amino acids will be absorbed from the food in the gut. At the same time, insulin will stimulate tissue uptake of competing amino acids from the circulation, and the plasma ratio of TRP to those amino acids (TRP : LNAA) will rise, favouring more TRP entry to the brain (Fernstrom, 1983; Yokogoshi \& Wurtman, 1986). Conversely, a high-protein meal, which would be less insulinogenic, results in absorption of large amounts of competing amino acids into the blood, especially the branched-chain amino acids, leucine, isoleucine and valine. On the other hand, TRP is scarce in most protein sources, and is readily metabolised on passage through the liver; thus, the plasma ratio of TRP to competing amino acids falls after a proteinrich meal (Schweiger et al. 1986b; Yokogoshi \& Wurtman, 1986; Christensen, 1993). Indeed, the protein-induced reduction in plasma TRP ratio often seems to be more marked than any carbohydrate-induced rise (Lieberman et al. 1986; Lyons \& Truswell, 1988; Wolever et al. 1988; Christensen \& Redig, 1993). Such effects also depend on the interval since, and nutrient content of, the last meal (Fernstrom \& Fernstrom, 1995).

This evidence is particularly relevant to dietary effects on mood and arousal, because 5-HT has long been implicated in sleep, as well as affective disorders such as depression and anxiety (Huether, 1988; Cowen, 1996). However, cognitive performance might also be affected, given the known role of 5-HT in responsiveness to environmental stimuli and stressors, impulsivity and information processing (Spoont, 1992; Cowen, 1996). Importantly, there is evidence that dietary availability of TRP can influence brain function in humans; for instance, feeding a TRPfree diet, which considerably reduced plasma TRP (and so presumably impaired 5-HT function; Stancampiano et al. 1997), induced depression in previously recovered depressives or in people with a genetic predisposition to depression (Benkelfat et al. 1994; Heninger et al. 1996). Furthermore, a TRP-free drink has been shown to impair performance on tests of visuospatial and visual discrimination learning (Park et al. 1994) as well as consolidation of long-term memory (Riedel et al. 1999). This latter memory impairment was found not to depend on mood changes or history of depression (Riedel et al. 1999).

There have been several recent reviews of this area (Bellisle et al. 1998; Reid \& Hammersley, 1999; Dye et al. 2000), so the earlier work will only be summarised briefly here. Spring et al. (1983) compared effects of protein-rich (86\% energy as protein, trace carbohy- 
drate) and carbohydrate-rich (80\% carbohydrate, protein-free) snacks (about $1088 \mathrm{~kJ}$ (260 $\mathrm{kcal})$ ) on mood and performance $2 \mathrm{~h}$ later. Results were variable, depending on age, gender and time of snack. However, there was a tendency for more sleepiness and calmness after the carbohydrate snack than after the protein-rich one. In subjects aged at least forty, lapses in sustained attention followed the carbohydrate lunch.

The increased sleepiness and calmness is compatible with an increase in 5-HT function, mediated by increased brain uptake of TRP, after the carbohydrate-rich, protein-free meal. Increased fatigue, and decreased alertness, have also been reported after oral TRP (50 mg/kg; Lieberman et al. 1983). However, that study did not show any effect of TRP on performance, so differential effects of carbohydrate and protein on performance may not simply reflect changes in TRP availability (although oral dosing with TRP is not equivalent to dietary manipulation of plasma TRP).

Furthermore, sleepiness (a common postprandial state) may have been inhibited after the protein-rich meal by a reduction in the ratio of TRP to other amino acids competing for uptake into the brain (Lieberman et al. 1986; Wolever et al. 1988), so reducing 5-HT synthesis. Comparing effects of carbohydrate to protein (Wolever et al. 1988; Christensen \& Redig, 1993) does not dissociate these two possibilities. Moreover, in a similar study comparing carbohydrate- and protein-rich meals on mood and performance, Lieberman et al. (1986) did not find differential effects of these macronutrients on fatigue or alertness, except for a transiently slower reaction time after the carbohydrate-rich $v$. the protein-rich lunch.

Another difficulty in comparing effects of carbohydrate and protein intake is that relative changes in mood and performance might be due to protein-induced raised plasma tyrosine (TYR) (Fernstrom \& Fernstrom, 1994; Markus et al. 1998), the precursor amino acid for synthesis of catecholamines (adrenaline, noradrenaline, dopamine), which also competes with LNAA for entry into the brain. In catecholamine systems where the neurones are firing rapidly, acute physiological increases in brain TYR, e.g. by feeding a high-protein diet, can raise TYR hydroxylation rate and catecholamine turnover (Fernstrom \& Fernstrom, 1994). Such systems include dopaminergic neurones involved in arousal, attention and motivation. Nevertheless, high-protein meals in human beings do not always raise the plasma TYR : LNAA, perhaps depending on nutritional status or time of day; a protein-rich meal after overnight fasting led to a fall in TYR : LNAA in healthy females, while in underweight anorectic women, the ratio rose, due to a marked postprandial increase in plasma TYR (Schweiger et al. 1986b). Also, unlike TRP, a large oral dose of TYR did not affect mood or performance (Lieberman et al. 1983).

By contrast to the above effects of almost pure carbohydrate or protein meals, a lunch of $55 \%$ energy as protein and $15 \%$ as carbohydrate altered attention, producing faster responses to peripheral stimuli, but greater susceptibility to distraction, with no differences in mood, compared with eating the reverse proportions of protein and carbohydrate (Smith et al. 1988). However, these meals would not be predicted to alter brain levels of either TRP or TYR (Yokogoshi \& Wurtman, 1986; Teff et al. 1989; Fernstrom \& Fernstrom, 1995), which could explain why post-lunch increases in lethargy and sleepiness were not affected by macronutrient composition in that study.

Evidence for an interesting synthesis of ideas concerning dietary manipulation of 5-HT function, performance and mood has been provided recently by Markus et al. (1998, 1999, 2000a). They hypothesised that raising brain TRP by eating a carbohydrate-rich-very-lowprotein diet might protect stress-prone subjects from the mood-lowering and performancereducing effects of an uncontrollable stressor. During stress, which is known to increase central 5-HT release (Wright et al. 1992), Markus et al. (1998) inferred that people with poor stresscoping ability might be susceptible to a functional deficit in 5-HT synthesis, which a dietary 
increase in TRP supply might alleviate. Thus, subjects were classified as high or low on a neuroticism scale ('stress proneness'), and then on one day given a high-carbohydrate-protein-poor breakfast, snack and lunch, followed by a challenging arithmetic test and a letter-recognition (memory scanning) task. On another day, subjects received protein-rich-low-carbohydrate meals, followed by the same stress induction and task. There was indeed some evidence to support the hypothesised interaction between stress proneness (neuroticism) and diet. Ratings of depression and vigour increased and decreased respectively after stress, except in the single condition where neurotic subjects had eaten the high-carbohydrate-protein-poor diet (which clearly elevated plasma TRP: LNAA). In this case, no change in depression or vigour occurred. Furthermore, this was the only situation in which cortisol did not increase after stress (Markus et al. 1998). In contrast to mood, performance on the memory task did not interact with diet and personality. However, reaction times were faster for all subjects after the proteinrich diet. These dietary effects on depression and cortisol in stress-prone subjects were essentially replicated by Markus et al. (2000b).

In another report using a similar design, Markus et al. (1999) did find an interaction between diet and personality on performance; in stress-prone subjects only, the carbohydraterich-protein-poor diet improved reaction time and reduced errors on more demanding letterrecognition tasks, compared with the protein-rich-carbohydrate-poor diet. The key difference between the design of Markus et al. (1998) and this study was that now the stress task allowed subjects to solve the arithmetic more easily (though heart rate and skin conductance did not differ from less controllable stress). It is not clear why such effects on performance should interact with stress controllability in this way, although a complex balance between catecholaminergic and serotoninergic activity might be involved, since both TRP and TYR availability are affected by these diets (Markus et al. 1998). Even though Markus et al. (2000a) replicated the dietneuroticism interaction effects on stress-induced depression and cortisol using high- and lowTRP protein diets ( $\alpha$-lactalbumin and casein, respectively), changes in TYR availability cannot be ruled out.

These results are particularly interesting in the light of a recent study of another response to protein-rich and protein-poor lunches (Gibson et al. 1999). The former but not the latter composition stimulated release of cortisol (Fig. 1). The protein-rich meal also prevented the post-lunch decline in positive affect (Fig. 2). Although there was no clear correlation between meal-induced cortisol release and post-meal mood changes (in only nine women), greater protein-stimulated cortisol secretion was associated with poorer overall psychological wellbeing (General Health Questionnaire). It has also recently been shown that an increase in positive affect 2-3 h after a protein-rich lunch is associated with a greater cortisol response to that meal, but only in subjects who ate a low-protein diet for $5 \mathrm{~d}$ previously (Gibson et al. 2000). These findings suggest a complex interaction between psychological wellbeing, nutritional status and corticosteroid reactivity. This hormonal response provides a possible alternative mechanism for differences in mood, and perhaps performance, after high-carbohydrate-protein-poor and lowcarbohydrate-protein-rich meals described earlier. To avoid repetition, more detailed evidence for a role for cortisol in effects on performance and mood is discussed later (p. 189), in the context of effects of glucose on mental performance.

\section{Effects of fat}

Recently, investigators have moved away from comparing protein and carbohydrate, to address the possible role of varying fat intake on mood and performance. Typically, fat and carbo- 


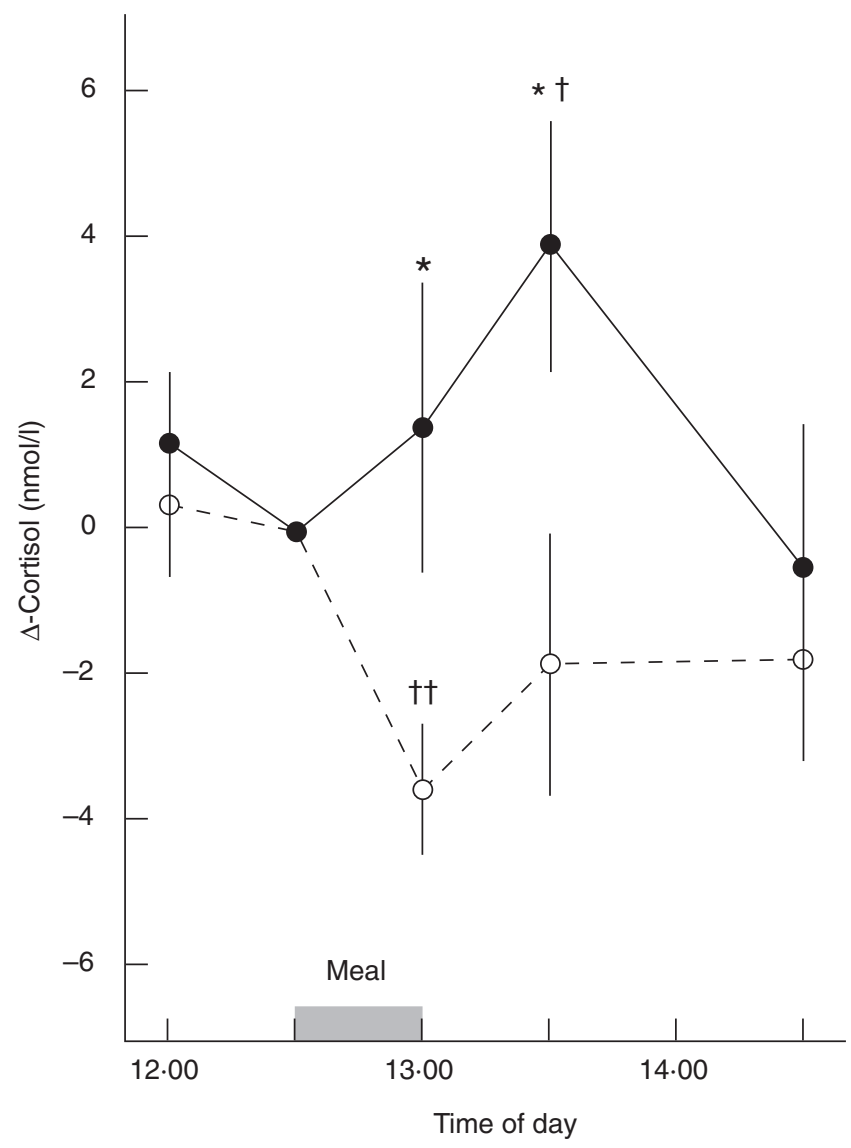

Fig. 1. Changes in salivary cortisol levels in women after eating a high-protein meal $(-, 32 \%$ energy as protein) and an equi-energetic low-protein meal (----, $5 \%$ protein). Data are mean values for nine women with their standard errors represented by vertical bars. *Significant difference between meal conditions at that time $(P<0.025)$. Significantly different from baseline: $\dagger P<0.05, \dagger \dagger P<0.01$. Data from Gibson et al. (1999).

hydrate levels were varied, with protein kept constant. Comparisons have been made for lowfat (e.g. 11-29\% of energy as fat), medium-fat (e.g. $45 \%$ ) and high-fat (e.g. 56-74 \%) breakfasts, mid-morning and midday meals (Lloyd et al. 1994, 1996; Wells \& Read, 1996; Wells et al. 1997) as well as intraduodenal infusions of lipid or saline (Wells et al. 1995). Again these studies have recently been reviewed (Bellisle et al. 1998; Dye et al. 2000), so we concentrate on discussing patterns in findings, and their possible mechanisms.

On balance, high-fat meals appear likely to increase subsequent fatigue and reduce reported alertness, but with little effect on cognitive performance, relative to high-carbohydrate-low-fat meals. However, there were inconsistencies relating to changes in specific moods and effects of meal timing. For instance, Lloyd et al. (1994) found that feelings of drowsiness, confusion and uncertainty increased after low- and high-fat lunches but not after a medium-fat lunch. There was also a post-lunch improvement in reaction time after the medium-fat but not low- or high-fat lunches; other performance measures were unaffected. In a similar study but with breakfasts, scores on a 'fatigue-dysphoria' mood factor were reduced after a low-fat-high- 


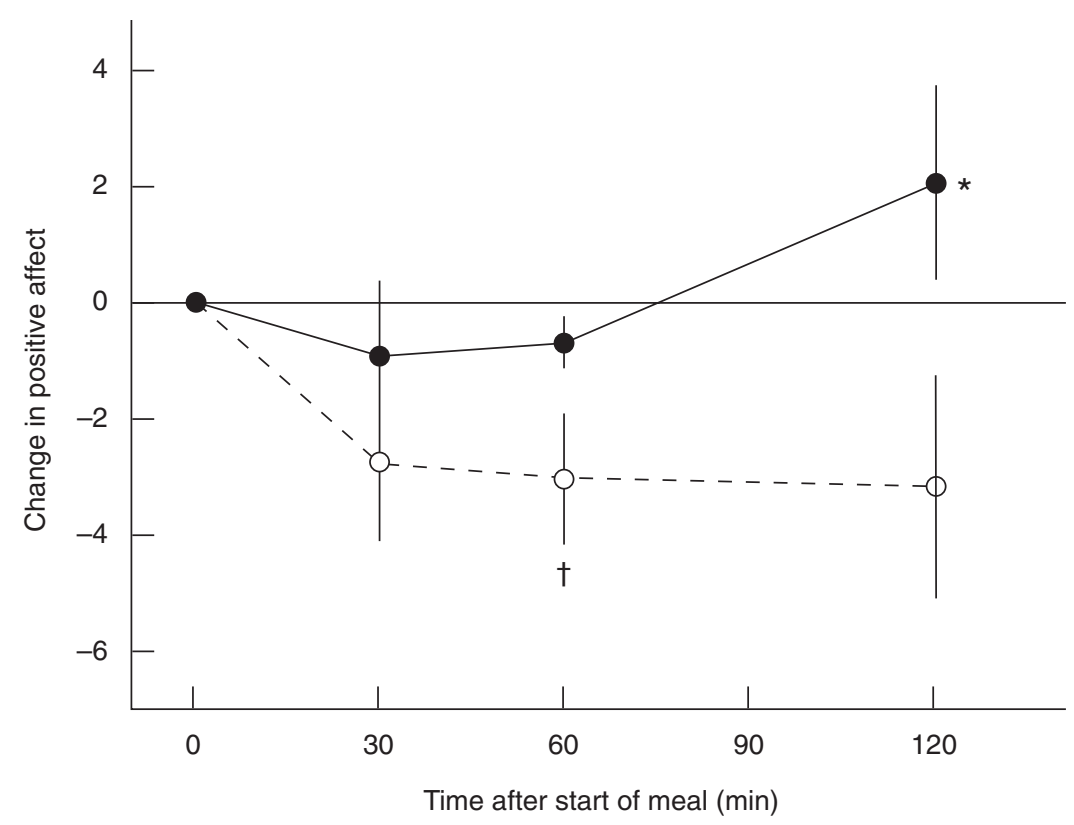

Fig. 2. Change in positive affect (differences from pre-meal baseline scores on the Positive and Negative Affect Schedule) in women after eating a high-protein meal $(-, 32 \%$ energy as protein) and an equi-energetic low-protein meal (----, $5 \%$ protein). Data are mean values for nine women with their standard errors represented by vertical bars. *Significant difference between meal conditions $(P<0.05)$. †Significantly different from baseline $(P<0.05)$. Data are from Gibson et al. (1999).

carbohydrate breakfast (Lloyd et al. 1996). Given that these subjects' habitual lunch was probably medium-fat and their typical breakfast closer to the low-fat-high-carbohydrate version, it seems plausible that mood may be adversely affected by meals that differ substantially in macronutrient composition from habitual ones (Rogers \& Lloyd, 1994; Dye et al. 2000), rather than by high- or low-fat per se. Another possibility is that similar mood effects could be induced (albeit by different mechanisms) by high-carbohydrate in one meal, and high-fat in the other; Cunliffe et al. (1997) found that $1674 \mathrm{~kJ}$ (400 kcal) drinks of pure fat or carbohydrate taken in the morning both increased an objective measure of fatigue (flicker fusion frequency) relative to a mixed-macronutrient drink, although the two single-nutrient drinks had opposite effects on plasma TRP : LNAA.

In the studies by Lloyd et al. (1994, 1996), mood differences were detected as early as 30 min after the meal, and so are unlikely to be due to changes in systemic nutritional state. Moreover, the meals were designed to disguise variation in fat level from the subjects. It is therefore possible that effects on mood may have resulted from discrepancies between subjects' expectations of certain post-ingestive effects, and the actual effects that resulted from neurohormonal responses to detection of specific nutrients in the duodenum and liver (Wells et al. 1995, 1998). A case in point may be the increase in tension, 90 min post-lunch, with increasing fat intake, reported by the predominately female subjects of Lloyd et al. (1994); we suggest that this finding might reflect an aversive reaction to (unexpected) fat-related post-ingestive sensations.

There is further evidence that any increase in fatigue directly related to fat is not likely to occur until the arrival of substantial amounts of fat into the duodenum 2-3 h later. Half an hour after low- or high-fat meals, alertness increased and sleepiness declined, whereas $2 \cdot 5-3 \mathrm{~h}$ later fatigue increased while arousal declined to the greatest extent after a high-fat meal (Wells et al. 
1995, 1997; Wells \& Read, 1996). By comparison, when lipid was infused directly into the duodenum, a decline in alertness was apparent much earlier, by 30-90 min after the meal (Wells et al. 1995). Wells \& Read (1996) found an increase in fatigue and reduction in vigour after a high-fat meal when eaten mid-morning but not at lunchtime (when mood changes were similar but independent of fat level). This could reflect either circadian effects or changes from habitual eating patterns. Nevertheless, on a sustained attention task, both speed and accuracy declined more rapidly after lipid infusion compared with saline, and after a high-fat $v$. low-fat midday meal (Wells et al. 1995).

A recent finding contrasts with the general trend for negative effects of fat ingestion: Fischer et al. (2001) fed subjects in the morning with equi-energetic (1674 kJ (400 kcal)) pure fat, protein or carbohydrate, in the form of sweet vanilla creams, designed to minimise differences in sensory acceptance between the foods. For the most part, a number of measures of cognitive performance (memory, attention and choice reaction time) improved after fat ingestion relative to those after protein or carbohydrate intake, with notably few effects on subjective ratings. This 'beneficial' effect of fat on postprandial performance was attributed to the demonstrated relative absence of glycaemic and hormonal (insulin, glucagon and cortisol) perturbations in the $3 \mathrm{~h}$ following fat ingestion. The limited effect of these pure nutrient meals on subjective measures might reflect suppression of expectations by the novel, disguised form of the foods. Even so, there was evidence for an arousing effect of protein relative to carbohydrate, in line with earlier findings.

How else might the proportion of fat ingested alter mood or mental performance? One possibility is via action of gastrointestinal and metabolic hormones. For instance, secretion of the gastric regulatory hormone, cholecystokinin $(\mathrm{CCK})$, is particularly sensitive to increases in duodenal non-esterified fatty acids from breakdown of dietary fat (Schwizer et al. 1997); moreover, exogenous CCK can reduce arousal as well as appetitive responses to meal preparation (Stacher, 1985).

Wells et al. (1997) found that plasma levels of CCK and somatostatin increased to a greater extent after a high-fat, low-carbohydrate ( $74 \%, 19 \%$, respectively) than after a low-fat, highcarbohydrate $(11 \%, 81 \%$,) equi-energetic meal, whereas the reverse was true for insulin and glucose (protein level was constant, if low, at $7 \%$ of energy). Gastrin increased substantially but equally after both meals. Oxytocin showed a small increase after the high-fat meal, but no consistent increase after the low-fat meal. Possible associations between levels of hormones and mood were examined by stepwise multiple regression analysis on (log-transformed) absolute hormonal levels. Levels of fatigue were positively related to levels of CCK but negatively to gastrin levels. Sleepiness was positively related to insulin, but negatively to gastrin. However, no interactions with meal type were reported in these regression analyses, and indeed, changes in gastrin were unrelated to meal type in any case. Wells et al. (1997) suggested that the negative correlations between gastrin and fatigue-sleepiness may reflect less fatigue-sleepiness in more anxious subjects throughout the study, since trait anxiety has been associated with higher gastrin levels (Uvnas-Moberg et al. 1993). Certainly, without differential effects of meal type, it seems likely that personality will be an important mediating variable. It is thus not clear, though still a possibility, that differential effects of meal composition on hormones such as CCK underlie meal-specific changes in mood.

\section{Effects of chronic dietary manipulations on mood and performance}

There have been few studies of changes in mood and performance after chronic changes of dietary composition, as opposed to total intake. Two studies found increased negative affect and 
anger after 1-3-week dietary regimens that differed substantially in macronutrient composition from subjects' usual diets (Deijen et al. 1989; Keith et al. 1991). However, it was not clear that this was due to specific nutritional effects, rather than a reaction to having to eat an unpalatable or monotonous diet.

Despite these methodological caveats, two other studies have linked greater positive affect and less negative affect with chronic ( $9 \mathrm{~d}$ or 6 weeks) relatively high-carbohydrate and lowprotein intake (Schweiger et al. 1986a; De Castro, 1987b), although performance was not measured. Furthermore, Schweiger et al. (1986a) found that better mood was associated with higher average 24-h plasma TRP : LNAA. Nevertheless, more chronic studies of this type are needed before definitive conclusions can be drawn: for instance, both mood and TRP : LNAA could be raised by poor compliance with the required energy restriction. Also, in a recent study in which rhesus monkeys were fed diets differing in protein content for sequential 4-week periods, TRP and the 5-HT metabolite, 5-hydroxyindoleacetic acid, in cerebrospinal fluid were higher when higher protein levels were consumed (Grimes et al. 2000). This suggests that chronic protein-rich diets might raise brain 5-HT turnover, which is against the established evidence, primarily in rodents, for acute meal effects where protein-rich meals lower brain TRP (Fernstrom \& Fernstrom, 1995). However, Grimes et al. (2000) found no association between these changes and plasma TRP : LNAA.

In fact, another mechanism is suggested by the finding that men eating a low-carbohydrate-protein-rich diet for $10 \mathrm{~d}$ had raised mean daytime plasma cortisol levels, compared with levels after eating a high-carbohydrate-low-protein diet (Anderson et al. 1987). No mood measures were reported in that study, but chronically high cortisol has frequently been linked to dysphoric mood and clinical depression (Checkley, 1996), although this might relate to dysfunction of brain 5-HT systems as well as the hypothalamic pituitary adrenal axis (Van Praag, 1996). Indeed, high baseline plasma cortisol predicts induction of depression by acute dietary TRP depletion (Åberg-Wistedt et al. 1998). By comparison with acute effects, any understanding of mechanisms underlying chronic effects will need to include neurotransmitter and neurohormone receptor adaptation (Huether et al. 1998).

\section{Associations between changes in performance and mood after meals}

Among those studies that have measured both mood and performance, there was some evidence that increased drowsiness or reduced arousal after meals was associated with deterioration in performance on vigilance or reaction time tasks (Smith \& Miles, 1986a; Lloyd et al. 1994; Wells et al. 1995). However, other studies have found impaired performance with increasing arousal (Conners \& Blouin, 1983), reduced arousal but no effect on performance (Lieberman et al. 1983), better mood but no effect on performance for fed $v$. fasted subjects (Smith et al. 1994c), or changes in performance but not mood (Smith et al. 1988; Fischer et al. 2001). This is perhaps not too surprising; causal relationships between mood and performance may well be neither contemporaneous (Owens et al. 2000) nor linear: for instance, optimal attention or memory may require some, but not too much, arousal, alertness and anxiety (McGaugh, 1989; Smith, 1992; Reid \& Hammersley, 1999). It is also possible that subtle changes in mood are less easily detected than effects on performance; mood rating scales typically have poorer resolution and higher measurement error than most measures of cognitive performance. Furthermore, effects on mood may be much more idiosyncratic than those on performance; in a laboratory test situation, two participants may be equally aroused, yet one could interpret the situation negatively, the other positively (Reid \& Hammersley, 1999). 
In summarising the influence of meals on arousal and performance, it is clear that substantial inconsistencies abound. However, it is likely that, in the presence of stressful or demanding situations, certain vulnerable individuals will be susceptible to behavioural effects of their recent diet (Huether et al. 1998). The consequence could be a change in cognitive function, mood or both. In the following sections, we explore ways in which the outcome can depend on psychological, physiological and nutritional vulnerabilities.

\section{Glucose and cognition}

There is a body of evidence suggesting that manipulations of blood glucose levels result in alterations in cognitive processing efficiency. This evidence takes two forms, the first consists of studies indicating that raising plasma glucose levels by means of a glucose-laden drink or food results in improvements in task performance. The second strand of evidence comprises studies indicating that the lowering of glucose levels, or at least mobilisation of alternative energy stores, by means of food deprivation, is associated with declines in cognitive function. This work is based on the assumption that, since glucose is the major source of fuel for the brain (for example, see Sieber \& Traystman, 1992), alterations in plasma levels of glucose will result in alterations in brain levels of glucose, and thus neuronal function. However, the strength of this notion lies in its common-sense plausibility, not in scientific evidence, and so the effects may well be epiphenomenal. For instance, blood glucose rises after all meals, when a plethora of neurohormonal responses are activated for glycaemic homeostasis (Widmaier, 1991). The roots of the glucose-cognition pairing can be found in the development of understanding, in the early 20th century, of adrenergic symptoms and cognitive confusion that follow diabetic hypoglycaemia. From this knowledge emerged the concept of reactive hypoglycaemia, in which non-diabetic patients complained of postprandial 'hypoglycaemic' symptoms, despite no apparent organic cause. Unfortunately, diagnoses far exceeded the evidence (Hutchinson, 1952; Service, 1999), leading to the emergence of a modern myth, influencing even research and health professionals (Lapp, 1981; Marks \& Teale, 1993). These groups can still be heard misguidedly advising diabetic and non-diabetic patients to avoid 'simple' carbohydrates (now an obsolete term) for fear of inducing glycaemic highs then lows, despite years of evidence that many foods high in polymeric starches, such as bread and potatoes, have the highest glycaemic indices (Foster-Powell \& Brand Miller, 1995; Food and Agriculture Organization/World Health Organization, 1998).

In relation to blood glucose and brain function, it should be noted that, in otherwise healthy individuals, the phrase 'hypoglycaemic symptoms' is misleading, in that the symptoms are not related to low blood glucose per se (Palardy et al. 1989; Snorgaard \& Binder, 1990). Rather, there is evidence that some individuals reporting 'hypoglycaemic symptoms' have higher glycaemic thresholds for counter-regulatory hormone release (Snorgaard et al. 1991), and greater $\beta$-adrenergic sensitivity and insulin resistance (Berlin et al. 1994) during falling blood glucose, than non-symptomatic controls. Moreover, during insulin-induced hypoglycaemia, deterioration of visual reaction time occurred at higher blood glucose levels in 'hypoglycaemics' than in controls (Snorgaard et al. 1991), and in a number of subjects there was no detectable effect of hypoglycaemia on cognitive function in more complex tasks. However, a sensitive psychophysiological measure of cortical function (P300 wave latency) did suggest impaired brain function when insulin-induced hypoglycaemia became sufficiently low (falling from 4.8 to $4.0 \mathrm{mmol} / \mathrm{l}$ arteriovenous plasma glucose) to elicit counter-regulatory hormone release, despite absence of adrenergic symptoms (De Feo et al. 1988). It is also notable that psychiatric disturbances such 
as anxiety and depression are commonly associated with self-reported hypoglycaemic symptoms (Berlin et al. 1994; Service, 1999).

The body of evidence concerning food deprivation, glucose and cognition is small and somewhat inconsistent in nature and relies on a combination of practice, the nature of the task battery employed and the exact meal that has been missed. For instance, as reviewed see p. 171, it has been found in several studies that missing breakfast impairs performance on measures of problem solving, decision time, and recall efficiency (Pollitt et al. 1981, 1983, 1996; Benton \& Sargent, 1992). Conversely, such brief periods of fasting are also associated with improved performance on recognition memory tasks (Pollitt et al. 1981; Green et al. 1997a). Moreover, those studies provided no consistent evidence that performance deficits were due to deprivation-induced falls in blood glucose. At best, there was some association between better performance and higher blood glucose, typically measured after testing, but this was not shown to be simply a consequence of having recently eaten. Instead, it is likely to reflect individual differences in neurohormonal influences on glucose synthesis and uptake, interacting with task involvement and stress reactions, as well as nutritional state; for instance, stressful tasks delay gastrointestinal transit and peak glucose in some but not all subjects (Wing et al. 1990; Blair et al. 1991). Further, it has been found that periods of fasting ranging from the missing of a single meal to complete food deprivation for $24 \mathrm{~h}$ need not produce any significant changes in cognitive processing efficiency at all (Green et al. 1995).

The evidence relating to improvements in task performance resulting from the ingestion of a glucose load is more consistent in nature, although its interpretation remains unclear. Several studies have shown that the ingestion of a glucose drink improves performance on a number of measures of cognitive function, relative to the ingestion of a placebo drink or no drink at all; but methodological factors complicate interpretation of these studies. For instance, compared with fasted subjects, Lapp (1981) reported greater recall of nouns by hyperglycaemic subjects previously administered a $150 \mathrm{~g}$ glucose load $1 \mathrm{~h}$ after a $300 \mathrm{~g}$ carbohydrate meal. However, any subjects with intermediate plasma glucose levels, after either fasting or the glucose load, were excluded. This selection procedure is likely to group subjects by variation in physiological processes maintaining blood glucose, rather than by effects of carbohydrate loading per se. Furthermore, although the concentration of the glucose drink was not given, it was very likely to have been hypertonic, leading to gastrointestinal discomfort (Shuford, 1959). The amount of carbohydrate ingested was vastly in excess of a standard oral glucose tolerance test (50-75 g glucose in 200-300 ml), which itself is hypertonic and known to induce nausea (Phillips et al. 1996). Therefore, it is possible that autonomic activation or other consequences of gastrointestinal malaise contributed to differences in performance. In later studies, both the concentration and form of glucose (e.g. monohydrate, oligomeric) were rarely given, though doses and concentrations tended to be smaller (25-50 g in $200-500 \mathrm{ml}$ ), so it is not always possible to assess the degree to which hypertonicity may have confounded results.

Benton et al. (1987) found that administration of a glucose drink (25 g glucose, equivalent to a large banana) to children, 1.5-2 h after lunch, improved reaction time, relative to the administration of a saccharin-sweetened placebo drink. This type of finding has been replicated several times, using a number of different performance measures (for example, see Benton, 1990; Benton \& Owens, 1993; Manning et al. 1993; Benton et al. 1994; Foster et al. 1998; for reviews, see Rogers \& Lloyd, 1994). In general, the pattern of results from these studies suggests that glucose administration selectively improves short-term memory or improves performance on vigilance tasks that require a large component of 'working memory' for their successful completion. However, several complications are worth noting: first, time since, and nature of, the previous meal was often not controlled (Benton \& Owens, 1993) and may have 
contributed to variable results (Sundell et al. 1989; Martin \& Benton, 1999); second, improved performance often did not depend on consuming a glucose load, but rather on the change in blood glucose over the test period, with or without a preload (Benton \& Owens, 1993; Benton et al. 1994); third, some studies found no association between glucose ingestion and cognitive function (Azari, 1991), or negative associations between memory performance and increased blood glucose (Manning et al. 1990); fourth, others have found that improvements in performance can be associated with both rising and falling blood glucose (Benton et al. 1994; Craft et al. 1994; Parker \& Benton, 1995; Donohoe \& Benton, 1999a), or that a beneficial effect of glucose depends on efficient glucose uptake and disposal (Hall et al. 1989; Manning et al. 1990; Craft et al. 1994); finally, Green et al. (2001) have recently shown that enhanced performance on a vigilance task after glucose ingestion was prevented in subjects who were told that the drink contained only the non-nutritive sweetener, aspartame. Thus, expectations can clearly be important; indeed, Melanson et al. (1999) found that blood glucose levels after an aspartamesweetened zero-energy drink were negatively correlated to the perceived sweetness of the drink.

\section{Mechanistic implications}

Given these inconsistencies, it is not surprising that a previous review of this literature up to 1994 (Rogers \& Lloyd, 1994) concluded that the results of these studies were equivocal and that there was little compelling evidence for the beneficial effects of glucose administration upon the cognitive function of healthy individuals. Rather, Rogers \& Lloyd (1994) suggested that the high baseline or rapidly rising levels of blood glucose, often observed in these studies to predict better performance, may reflect increased sympathoadrenal and adrenocortical activity, including an increase of plasma adrenaline, noradrenaline, and cortisol.

Glucose, sympathetic arousal and cognitive performance. There is considerable evidence that adrenergic arousal improves cognitive performance via peripheral $\beta$-adrenoceptor activation (McGaugh, 1989; Nielson \& Jensen, 1994) as well as raising blood glucose (Gold, 1995). However, increased sympathoadrenal output raises blood glucose primarily via inhibition of uptake and disposal (Sherwin \& Saccà, 1984), and there is no direct evidence that this is the mechanism underlying these glucose-related improvements in human performance. Adrenergic antagonists oppose the effects of arousal, but not glucose, on memory (Nielson \& Jensen, 1994; Gold, 1995). Furthermore, it has been found that, whereas manipulating arousal levels by means of incentive motivation does produce selective improvements in performance, those improvements are unrelated to blood glucose levels (Green et al. 1997a). Indeed, sympathoadrenal arousal during a psychologically challenging performance test does not necessarily lead to any change in plasma glucose in the absence of intake (Hagström-Toft et al. 1993).

Donohoe \& Benton (1999b) hypothesised that an important methodological difference between studies in this area may be whether or not subjects were given a demanding task very soon after the glucose drink. They compared performance of groups with or without a demanding test immediately after either a glucose or placebo drink. Having to perform the demanding task improved subsequent word recall after a glucose drink, suggesting a possible interaction with adrenergic enhancement of memory. Importantly, however, this arousal effect was diminished in those subjects whose blood glucose was rapidly rising by $20 \mathrm{~min}$. Insofar as the timing implies rapid absorption of glucose, we suggest one possibility is that these subjects were less aroused by the demanding test, and so performed worse subsequently, compared with subjects whose blood glucose was not yet rising. That is, in those latter subjects, glucose absorption may 
have been delayed by greater arousal in response to the demanding task (Wing et al. 1985; Blair et al. 1991). Indeed, differing patterns of postprandial blood glucose changes have been associated with personality factors such as extraversion and introversion (Christie \& McBrearty, 1979), which in turn could interact with perceived demands of the task. However, it should also be remembered that over-arousal might lead to poorer cognitive performance (Reid \& Hammersley, 1999), and rising blood glucose could reflect less efficient cell uptake and disposal from the circulation (Kennedy \& Scholey, 2000).

A further complication that can cloud interpretation is how recently subjects have eaten a meal before glucose loading and testing. A recent meal may interact with the impact of arousal on blood glucose as well as with the effect of further glucose intake (Martin \& Benton, 1999). Moreover, fasting has been associated with enhanced speed of performance on memory tasks in some studies (Benton \& Owens, 1993; Green et al. 1997a), but poorer recall levels in others (Martin \& Benton, 1999).

In considering a possible role for arousal in mediating glycaemic effects on performance, it should be noted that ingestion of food, and even pre-ingestive sensory stimulation by food (Nederkoorn et al. 2000), will elicit acute sympathetic activation, at least partly to regulate blood pressure homeostasis during diversion of blood to the splanchnic bed (Lipsitz et al. 1993; Vaz et al. 1995). Glucose ingestion is no exception (Mathias, 1990; Kennedy \& Scholey, 2000), whereas involvement of insulin release depends on the time of day (Biston et al. 1996). Cardiovascular responses to meals also depend on both meal size and time of day; heart rate and systolic blood pressure rose after a $1807 \mathrm{~kJ}(432 \mathrm{kcal})$ breakfast but not after a $531 \mathrm{~kJ}(127 \mathrm{kcal})$ breakfast, whereas these measures increased after both a $573 \mathrm{~kJ}(137 \mathrm{kcal})$ and a $5402 \mathrm{~kJ}$ (1291 kcal) lunch (Macht, 1996). Furthermore, afferent vagal nerve stimulation, for instance by absorbed nutrients or gastrointestinal hormones, is known to enhance memory retention in human subjects (Clark et al. 1999).

Nevertheless, Kennedy \& Scholey (2000) found that heart rate increased further during cognitive performance testing, irrespective of whether glucose or a placebo drink had been ingested. Working memory performance was better in subjects with lower baseline heart rates (who had greater task-induced increases). Better pancreatic function may also be important, since a greater decline in blood glucose during the tasks, after glucose ingestion, was associated with better performance. However, other aspects of individual physiological efficiency and arousal responses need to be considered, as pre-task plasma glucose levels correlated positively with performance, whether or not glucose had been ingested (Kennedy \& Scholey, 2000).

In addition, recent understanding of the use of lactate as fuel by neurones, and the importance of glycogen stores in astrocytes, suggests a more complex yet orchestrated relationship between arousal, glucose uptake and performance (Rennie, 2000). Astrocytic glycogen shows rapid turnover during euglycaemia, so is not a passive store, but an active supplier of energy substrate to neurones (Fillenz et al. 1999), as well as protecting neuronal survival during glucose deprivation (Ransom \& Fern, 1997). Ide et al. (2000) have shown that, during high energetic demand such as when exercising (and perhaps during stress), the brain metabolises lactate from muscle and astrocytic glycolysis, then during recovery, rapid glucose uptake is stimulated to replenish depleted glycogen stores. Indeed, lactate infusion is known to ameliorate cognitive deficits during hypoglycaemia (Maran et al. 1994).

It is also now clear that the increase in glucose delivery by blood to the activated brain, accompanying increased regional cerebral blood flow, primarily results in uptake of the glucose by astrocytes, and storage as glycogen (very little of the increased available $\mathrm{O}$ is used at first) (Fillenz et al. 1999). That is, the extra glucose is not immediately used by neurones. The release of glucose to activated neurones from astrocytic glycogen, for instance during acute stress, is 
probably controlled by the action of noradrenaline on astrocytic $\beta$-adrenoceptors (Fillenz et al. 1999). This astrocytic buffering effect on glucose and $\mathrm{O}$ use by neurones might underlie the improvement in delayed but not immediate recall seen after $\mathrm{O}_{2}$ inhalation (Winder \& Borrill, 1998); thus, it appears to be memory consolidation, not retrieval, that is improved by inhalation of $\mathrm{O}_{2}$ (Scholey et al. 1998). Further, it has recently been proposed that deficient catecholaminergic control of this astrocyte-mediated neuronal energy regulation underlies impaired cognition in Attention-Deficit-Hyperactivity Disorder (Todd \& Botteron, 2001). Therefore, it seems likely that many of the findings of studies relating glucose to cognitive performance reflect an interaction between physiological efficiency, glucoregulation, ability to cope with, and involvement in, stressful tasks, and brain function.

The one area where glucose administration is most strongly associated with improvements in cognition is in its application to groups who are nutritionally or metabolically 'at risk', such as the elderly (e.g. Parsons \& Gold, 1992; Manning et al. 1993; Messier et al. 1997); for reviews, see Messier \& Gagnon, 1996). Further support for this vulnerability can be seen in two studies which have directly assessed the relative effects of glucose administration in elderly and young, healthy adults (Hall et al. 1989; Manning et al. 1997). In both cases, it was found that the administration of a glucose drink selectively enhanced the memory performance of elderly subjects but not that of young, healthy subjects. However, this age difference may partly depend on the relative demands of the task; a glucose load can enhance performance in young adults given more demanding tests of memory and attention (Korol \& Gold, 1998; Donohoe \& Benton, 1999b). Other recent evidence emphasises the importance of individual glucose regulation in predicting a memory-enhancing effect of carbohydrate loading in the elderly; Kaplan et al. (2000) found that mashed potato and barley, as well as glucose ingestion, improved cognitive performance specifically in elderly subjects with poor baseline memory performance and poor pancreatic $\beta$-cell function. This effect was independent of changes in blood glucose.

Glucose, cortisol and cognition. One potential physiological mediator of an association between glucoregulation and cognition is the hypothalamic pituitary adrenal axis, and particularly the release of the glucocorticoid hormone, cortisol. There are several reasons to consider a link between cortisol and effects of glucose on cognitive performance. Performance on shortterm memory (Brandenberger et al. 1980) and declarative memory tasks (Kirschbaum et al. 1996) has been found to be strongly inversely correlated to the size of cortisol rise induced by a challenging task. Moreover, acute administration of cortisol impairs performance on working memory (Lupien et al. 1999), declarative memory and spatial thinking tasks, but not procedural memory (Kirschbaum et al. 1996). These effects probably involve action of cortisol on hippocampal neuronal function; receptors binding cortisol are abundant in the hippocampus (De Kloet et al. 1993), a brain region strongly implicated in declarative memory (Newcomer et al. 1994). There is also evidence for rapid, non-genomic, membrane-receptor modulation of memory by glucocorticoids (Filipini et al. 1991), which might be involved here. In addition, glucocorticoids can inhibit glucose uptake into the hippocampus (Horner et al. 1990).

The typical rise in cortisol following a stressful psychological task was seen in subjects given a glucose load $(100 \mathrm{~g} / 400 \mathrm{ml}) 1 \mathrm{~h}$ before the task, but not in fasted subjects (Kirschbaum et al. 1997). Furthermore, plasma glucose level after the load predicted the extent of stressinduced rise in cortisol, whereas in the absence of stress, cortisol did not change following the glucose load (Kirschbaum et al. 1997). This dependence of a stress-induced rise in cortisol on the non-deprived state might help explain improved performance on certain tasks in children who missed breakfast, and in overnight fasted adults, in whom speed of performance on 
memory tasks was enhanced (Benton \& Owens, 1993; Green et al. 1997a): perhaps those outcomes particularly benefited from a lack of cortisol release during the tests.

One possible resolution of these and earlier findings (e.g. where falling glucose or increased insulin secretion predicts better performance) may be that faster uptake and disposal of glucose (after a glucose load) would be associated with a smaller rise in cortisol during a stressful test of performance, and so would thus minimise cortisol-induced deterioration of memory. This is also in line with the accumulating evidence that poor glucoregulation, and physiological inefficiency, is associated with poor cognitive performance following glucose administration (Hall et al. 1989; Craft et al. 1994; Kaplan et al. 2000; Kennedy \& Scholey, 2000). For instance, peak plasma glucose achieved after a glucose or placebo load has repeatedly been shown to predict poorer performance on memory tasks, even on days when no glucose load was given (Hall et al. 1989; Manning et al. 1990).

The critical interaction is likely to be between glucoregulatory processes and the impact of a challenging task; thus, glucose (or other food) ingested before a stressful challenge may promote cortisol secretion, the more so in vulnerable individuals with poor glucoregulation. By comparison, in overweight insulin-resistant subjects at rest (unstressed), both higher fasted and post-glucose-load blood glucose levels were associated with lower morning plasma cortisol levels after oral glucose load (Fernández-Real et al. 1997). Such subjects are also likely to show greater cortisol responses to stress (Rosmond \& Björntorp, 2000).

The interaction of glucoregulation, cortisol and cognitive performance might also mediate earlier findings of relationships between personality type and effects of meals on performance (Smith, 1992). More direct evidence is needed, since associations between personality variables and cortisol are complex (Pruessner et al. 1997); but positive coping strategies have been found to predict lower cortisol responses to stress (Bohnen et al. 1991). Furthermore, when cortisol release is elicited by a stressful task before a midday meal, the cortisol response to the meal is suppressed in proportion to the amount of cortisol released during the pre-meal stressor (Brandenberger et al. 1980). This has implications for interpretation of pre- and post-meal changes in performance. For instance, it might explain the resistance of anxious subjects to a post-lunch dip in performance (Smith, 1992), if the impact of the meal on cortisol was lessened in those subjects by prior cortisol release.

Glucose, cholinergic neural function and memory. Other work in this area has centred on the hypothesis that the effects of glucose administration mostly benefit memory function (for example, see Gold, 1986). This is a hypothesis which is consistent with findings of beneficial effects of glucose on the performance of tasks which, whilst not primarily being measures of memory capacity, have high concurrent processing (or working memory) loads (for example, see Kennedy \& Scholey, 2000). One possible mechanism underlying this effect may be related to the role played by glucose in the synthesis of the neurotransmitter acetylcholine (Gold, 1995), which work in the field of Alzheimer's dementia has identified as being associated with memory (for example, see Fibiger, 1991). Together with dietary choline, the co-substrate for synthesis of acetylcholine is acetyl CoA, which is in part a by-product of glucose metabolism.

However, whereas glucose availability can influence acetyl CoA production, the systemic or central synthesis and release of acetylcholine clearly will not simply depend on plasma glucose; for cholinergic enhancement of memory by glucose availability, complex and specific mechanisms would need to be invoked. Glucose-enhanced release of central acetylcholine may depend on increased activity of cholinergic neurones, as during demanding tests of learning and memory. For instance, glucose injection in rats further enhances hippocampal release of acetylcholine stimulated by task performance, whereas no such effect is seen in resting rats (Korol \& Gold, 1998). 


\section{The psychological effects of dieting to lose weight}

Dieting to lose weight is one of the most common food choice-related behaviours undertaken in the developed world. To illustrate this point, it is estimated that, at any one time, $12 \%$ of women between the ages of 12 and 64 are following a weight-loss programme (Gregory et al. 1990) and that $90 \%$ have attempted weight-reducing diets at some time in their lives (Ogden, 1992). Although the effects of acute food deprivation (at least in terms of missing individual meals or deprivation for periods of up to $24 \mathrm{~h}$ ) are outlined see p. 171, there is also a body of evidence which indicates that more self-induced attempts at weight control by means of energy reduction are associated with a range of negative psychological impairments. Whilst it is certain that extreme cases of self-induced starvation such as those characteristic of anorexia nervosa result in impairments of neuropsychological function (for example, see Fox, 1981), it is generally considered that these impairments result from the gross changes in brain anatomy (such as ventricular enlargement and sulcal widening) which accompany extreme starvation (for example, see Kingston et al. 1996).

In contrast non-psychopathologically induced attempts at weight reduction are also associated with psychological problems. Dieting to lose weight has been associated with swings in mood state (Tiggemann, 1994), depression (Smoller et al. 1987) and increased concern with body shape (Warren \& Cooper, 1988; Green \& Rogers, 1993).

Dieting has also been associated with impaired cognition (Wing et al. 1995). For example, female dieters performed more poorly than non-dieters on a task of sustained attention (Rogers \& Green, 1993), as well as poorer performance on immediate free recall and simple reaction time tasks (Green et al. 1994). In addition, this study found that motor performance (as assessed by two-finger tapping speed) was actually better in dieters than non-dieters, indicating that these effects could not be explained in terms of a simple slowing of overall motor speed or lack of motivation amongst dieters. Further, performance has been demonstrated to be poorer, within the same individuals, when dieting than when not dieting (Green \& Rogers, 1995), indicating that the phenomenon is related to dieting per se, rather than pre-existing individual differences between dieters and non-dieters. Interestingly, this study is notable for two further aspects. First, the impairments in performance were found even amongst those dieters who reported not having lost any weight over the course of the diet and, second, that the impairments were most marked in those who had been dieting for the shortest period of time. These two factors combine to suggest that the dieting-related phenomenon is psychological, rather than physiological in nature, a hypothesis that will be elaborated upon at a later point in the present review.

Further work has attempted to fractionate the nature of the deficit in cognitive function associated with the attempt to lose weight by means of dieting. Rather than representing a global deficit, it has been demonstrated that the cognitive processing deficit associated with naturalistic, uncontrolled dieting is fundamentally a deficit of 'working memory' (Green et al. 1997b). Working memory (Baddeley, 1986) can be conceptualised as being the fundamental cognitive processing system, in that it serves to allocate limited cognitive processing capacity to other ongoing cognitive operations in order of their relevance or importance to an individual. In addition, it has been found (Green \& Rogers, 1998) that the magnitude and precise structure of these deficits is comparable to those which result from the preoccupying cognitions characteristic of high levels of anxiety (for example, see Darke, 1988) and clinical depression (for example, see Channon et al. 1993).

This latter finding, in conjunction with the finding that dieters have impairments in cognitive function in the absence of any significant weight loss over the course of the diet (Green \& Rogers, 1998), leads to the conclusion that these deficits are psychological in nature. They may 
be best explained in terms of a threshold hypothesis of the impact of intrusive, task-irrelevant, thoughts on cognitive processing efficiency. Non-dieting, restrained eaters are characterised by an enduring preoccupation with body shape (Herman \& Polivy, 1980) which can be assumed to impose some capacity restraint on working memory. When combined with the state-related feelings of hunger and food craving resultant from the reduced energy intake experienced during attempted weight loss (Hart \& Chiovari, 1988), it is hypothesised that a threshold of preoccupation is crossed, whereby insufficient working memory capacity is available to perform efficiently the tasks presented to dieters in experimental settings. This hypothesis is supported by studies which have demonstrated no clear effects of weight loss upon cognition in the absence of any pre-existing concerns with weight and body shape (for example, see Deijen et al. 1989; Kretsch et al. 1997; Shukhitt-Hale et al. 1997). The central conclusion which can be drawn from this work, therefore, is that the cognitive load imposed by food cravings and hunger (in addition to pre-existing concerns with body shape and self-esteem) in dieters is a causal factor in their impaired cognitive task performance. One potential problem with such a hypothesis is the finding that highly restrained eaters (and dieters are, by definition, restrained eaters) do not experience significantly more food cravings than unrestrained eaters (Hill et al. 1991). However, rather than weighing against this hypothesis, this finding serves to outline the conceptual and practical distinction between high levels of dietary restraint and actual dieting behaviour outlined by Lowe (1993). Whilst high levels of restraint are a necessary precondition of starting and maintaining a diet, it is not necessarily the case that an individual will be on a diet if they are a restrained eater. Hill et al. (1991) present no information on the current dieting status of their subjects.

Although there are a number of studies (cited above) which tend to support this hypothesis, there is some evidence that experimentally induced weight loss negatively affects cognitive function. Wing et al. (1995) reported that the administration of a low-carbohydrate diet (2297 $\mathrm{kJ}(549 \mathrm{kcal}) / \mathrm{d})$ over $28 \mathrm{~d}$ amongst obese subjects was associated with impaired performance on a trail-making task, relative to a group administered a low-fat diet $(2469 \mathrm{~kJ}(590 \mathrm{kcal}) / \mathrm{d})$. This interpretation can, however, be criticised on several grounds. Foremost of these is that, although $\beta$-hydroxybutyrate levels (a metabolic indicator of starvation) rose significantly over the whole $28 \mathrm{~d}$ of the diet, trail-making task performance was only significantly impaired at $7 \mathrm{~d}$ of dieting, compared with baseline. Subsequent measurements showed that trail-making performance after $28 \mathrm{~d}$ of low-carbohydrate dieting was actually better than at baseline. This was further confounded by marginally significant baseline differences between trail-making performance. More recent work has also indicated that simple weight loss per se may not be a fully adequate explanation for the impairments in cognition found amongst naturalistic dieters. Buffenstein et al. (2000) found that a 6-week weight-reducing diet $(3347 \mathrm{~kJ}(800 \mathrm{kcal}) / \mathrm{d})$ was associated with impairments in simple reaction time, although choice reaction time was actually improved amongst participants subjected to this regimen.

The evidence presented so far has supported the conclusion that dieting-related impairments in cognition result from psychological factors, rather than the gross consequences of food deprivation. It is still possible, however, that some of the more subtle physiological consequences of food deprivation may play a mediating role in this phenomenon. The most widely investigated of these possible mechanisms concerns that of a dieting-related change in serotoninergic neurotransmitter function, possibly resulting from lowered plasma TRP : LNAA impairing 5-HT synthesis (see p. 178). There is evidence that moderate chronic lowering of plasma TRP : LNAA, by dieting (e.g. $4184 \mathrm{~kJ}(1000 \mathrm{kcal}) / \mathrm{d}$ ) for up to 3 weeks (Anderson et al. 1990), selectively enhances brain 5-HT receptor function in women (though not in men) (Goodwin et al. 1987; Walsh et al. 1995; Cowen et al. 1996). 
There are, however, at least three potential problems with such an argument. The first of these concerns the order of magnitude of TRP depletion produced by the two methods outlined see pp. 178 and 192, i.e. TRP-deficient amino acid preloads or restricted energy intake. In general, the amino acid drink method tends to deplete TRP by some 70 to $80 \%$ (for example, see Park et al. 1994). The diet method, however, tends to deplete plasma TRP by roughly 10-20\% (for example, see Cowen et al. 1996; Wolfe et al. 1997). It is, therefore, uncertain whether naturally occurring dieting would reduce TRP sufficiently to affect cognitive processing efficiency; the dietary regimen imposed in these studies is somewhat more severe than that of most typical weight-loss diets, with a daily energy intake of $4184 \mathrm{~kJ}(1000 \mathrm{kcal})$. The second concern is that previous studies which have demonstrated dieting-related impairments in cognition have found these deficits even in dieters who have not reported any weight loss over the course of their diet (Green \& Rogers, 1995). Further, it has been demonstrated that a similarly restrictive weightloss regimen administered over a 15 -week period produces no significant impairment of cognitive function (Kretsch et al. 1997). Third, animal studies show that acute starvation increases 5-HT synthesis and turnover in the brain, while longer-term starvation promotes 5-HT availability at the synapse by down-regulating presynaptic 5-HT re-uptake sites (Huether et al. 1998).

Serotoninergic function may also be affected in dieters by methods other than that of a simple reduction in TRP intake resulting from energy restriction. One of the most common weight loss strategies undertaken by dieters is an alteration in the fat : carbohydrate of the diet, with dieters eating a greater proportion of carbohydrate-rich foods (for example, see Tepper et al. 1996). Such foods, if very low in protein and eaten after fasting, might increase central 5-HT synthesis acutely. However, that is unlikely to account for the impaired cognitive performance, since it has been found that a carbohydrate-rich diet actually improves some task performance, albeit only in neurotic subjects (Markus et al. 1999). Nevertheless, a diet particularly low in some fats might impair cognition (see p. 180; Fischer et al. 2001).

Although these are powerful arguments against a simple serotoninergic explanation of the impairments in cognition found amongst dieters, they remain, as yet, unproven by published experimental evidence. Even if future work fails to confirm this hypothesis, it may very well be the case that other nutritional (rather than psychological) variables may mediate the phenomenon of impaired cognitive function in weight-loss dieting. For instance, there is some suggestion that plasma haemoglobin concentrations mediate task performance during experimentally controlled weight loss (Kretsch et al. 1998). In this case, however, the argument outlined above as to whether experimentally controlled weight loss is a good model for naturalistic dieting behaviour can still be raised.

\section{Cholesterol levels and cognitive function}

Aside from the previously mentioned negative psychological effects of attempted weight loss, there is a body of literature indicating that other dietary changes, such as attempts at lowering cholesterol levels, are similarly associated with psychological impairments. Reductions in plasma cholesterol levels are a major health goal for the Developed World, as it is seen as an essential factor in the prevention of CHD (AHA/Medical Scientific Statement, 1997) and ischaemic strokes. Nevertheless, a number of studies indicated that low or decreasing levels of cholesterol are associated with increased rates of death from suicide (for example, see Gallerani et al. 1995), incidence of depression (Glueck et al. 1994) and impaired cognitive function (in terms of choice reaction time; Benton, 1995). There is also some cross-sectional data to suggest 
that higher cholesterol levels are associated with better cognitive function (Muldoon et al. 1997). It is the case, however, that these findings are inconsistent, with some studies finding no relationship between low cholesterol levels and depression (for example, see Strandberg et al. 1993).

It should be remembered that these studies are cross-sectional in nature, with the resultant difficulty in inferring causality. There are, however, two recently published clinical intervention trials which have demonstrated that the active reduction of cholesterol levels, either by means of dietary or pharmacological intervention, exerts negative psychological effects. Wardle et al. (2000) administered two forms of a 12-week dietary intervention to hypercholesterolaemic patients (one designed to lower overall plasma lipid levels, one designed to alter the intake ratio of monosaturated and polyunsaturated fats to saturated fats, and a non-intervention control group). It was found that, although mood state and a number of other markers of psychological wellbeing improved in all three groups, performance on a cognitively demanding measure of the ability to sustain attention was relatively impaired in the two lipid-lowering diet groups relative to the untreated control group. Further, performance on this task was found to correlate significantly with change in plasma cholesterol levels over the course of the intervention. Another study (Muldoon et al. 2000) found that a pharmaceutical cholesterol-lowering intervention (Lovastatin, administered at a dosage of $20 \mathrm{mg} / \mathrm{d}$ for a period of 24 weeks) impaired performance on a range of measures of cognitive function in subjects with hypercholesterolaemia. Specifically, it was found that the group who were administered the cholesterol-lowering drug failed to display the practice-related improvement in performance characteristic of the placebo-administered group on tasks measuring vigilance, psychomotor speed and mental flexibility. In addition, although there were no significant correlations between change in task performance and change in cholesterol levels (as found by Wardle et al. 2000), there were significant correlations between final assessment levels of task performance and final assessment cholesterol levels. As with the Wardle et al. (2000) study, there were no significant changes in other markers of psychological wellbeing associated with Lovastatin. Taken as a whole, therefore, these two studies appear to indicate that the active attempt to reduce plasma cholesterol levels, whether by pharmacological or dietary means, is associated with negative cognitive outcomes.

One mechanism which has been hypothesised to underlie these effects centres on the role of cholesterol in maintaining the integrity of the lipid bi-layer of which cell walls are constructed. Although this hypothesis is discussed at greater length elsewhere (Kaplan et al. 1997), a brief summary follows. It is hypothesised that alterations in plasma cholesterol levels structurally affect the fluidity of cell membranes, including neurones. In the case of neurones, alterations in membrane fluidity will have implications for neurotransmitter and synaptic function. Indeed, there is evidence to suggest that the cholesterol content of surrounding plasma influences the cell membrane phospholipid to cholesterol mole ratio, this being an indirect measure of membrane fluidity (McMurchie \& Patten, 1988). It has been further hypothesised that one of the neurotransmitter systems particularly affected by alterations in plasma cholesterol concentrations may be that of 5-HT. This is supported by evidence that (in vitro) 5-HT receptor binding can be increased or decreased as a function of the addition or removal of cholesterol from brain synaptic membranes (Heron et al. 1980). Since 5-HT is implicated in a wide range of psychological phenomena, from frontal lobe function to arousal levels and appetite control, any reliable effects exerted by cholesterol on 5-HT function may be expected to demonstrate profound psychological effects.

Interestingly, it has recently been proposed that serotoninergic deficits related to neuronal membrane fluidity may reflect the balance of $n-3$ and $n-6$ essential fatty acids (Hibbeln et al. 
1998). It is suggested that cholesterol levels could be a marker for variation in these essential fatty acids, which have been linked to cognitive impairment and psychopathology (Youdim et al. 2000).

\section{Age-related cognitive decline and vitamin status}

There is a large body of evidence which indicates that vitamin status is an important mediator in the maintenance of efficient cognitive processing. It is a common finding that psychological function decreases with age. The impairments in memory associated with ageing can lead to inattentiveness, poorer judgements and planning ability, slowed reaction times and impaired information processing (Craik et al. 1995), leading to an increased vulnerability to accidents. This has obvious implications for health care, since the elderly consume a disproportionately large proportion of health care resources than would be predicted from their numbers in the population as a whole. It is also the case that a major determinant of the quality of life for elderly individuals is the efficiency of their mental processes. Although the decline in mental abilities of healthy individuals is slight before the age of 70 years, some groups seem particularly at risk. For instance, elderly inactive isolated individuals (so-called 'disengaged home makers') have shown substantial declines in cognitive function during longitudinal studies (Sternberg, 1986). Whilst decline in mental abilities is, of course, associated with dementia, this does not appear to be an identifiable cause of the loss of cognitive processing abilities for many individuals. There is some doubt as to whether these declines represent a natural, inevitable function of the ageing process or are due to small pathological changes in the brain resulting from conditions accompanying ageing. It has, for instance, been suggested that the decline in cognitive function which accompanies normal ageing is largely attributable to secondary factors such as disordered sleep patterns, alcohol consumption, elevated serum cholesterol, raised blood pressure, diabetes and reduced cerebral blood flow (Rinn, 1988). These are factors which, to varying degrees, have a nutritional component.

Several Department of Health surveys carried out between 1968 and 1979 revealed problems of vitamin deficiency amongst the elderly population in the UK. Although the proportions vary according to each survey, it has been consistently found that large numbers of free-living elderly individuals over 70 years of age suffer from deficiencies in a number of vitamins. For instance, a substantial portion of the elderly living in the UK experience deficiencies in riboflavin, cobalamin (vitamins $\mathrm{B}_{2}$ and $\mathrm{B}_{12}$ ) and serum folate. It is possible that these sub-clinical deficiencies are a factor in the cognitive decline observed with ageing.

\section{B-complex vitamins, folate and neural function}

A number of vitamins have functional utility in the maintenance of the central and peripheral nervous system. Deficiencies in the B-vitamin group (thiamin, $\mathrm{B}_{2}, \mathrm{~B}_{6}, \mathrm{~B}_{12}$ and folate) have been linked with conditions such as irritability, depression, peripheral neuropathy (both $\mathrm{B}_{6}$ and $\mathrm{B}_{12}$; Rosenberg \& Miller, 1992) and myelin degeneration (Rosenberg \& Miller, 1992). One possible route whereby deficiencies in these vitamins may affect cognition relates to their role in the metabolism of the S amino acid homocysteine. Plasma levels of homocysteine have been variously inversely correlated with levels of $\mathrm{B}_{12}$ (Koehler et al. 1996; Lussier-Cacan et al. 1996), vitamin $\mathrm{B}_{6}$ and folate (Selhub et al. 1993). Indeed, serum concentrations of the homocysteine metabolite methylmalonic acid can be used as an indirect marker of $\mathrm{B}_{12}$ deficiency 
(Lindenbaum et al. 1988). Elevated levels of homocysteine have been shown to be an important factor in the development of a number of vascular problems such as occlusive vascular disease, atherosclerosis and cerebrovascular disease (for an extensive review, see Ueland \& Refsum, 1989). Importantly, it has been found that supplementation with a range of B-complex vitamins reduces serum homocysteine levels in both elderly (Koehler et al. 1996) and younger (Woodside et al. 1998) populations.

It is possible, therefore, that subclinical deficiencies of B-complex vitamins amongst the elderly UK population are a causal factor in the decline in cognitive processing efficiency amongst this group (this being either a problem of low intake or lowered absorption) and that the mechanism by which this occurs is raised homocysteinaemia. Indeed, there is evidence suggestive of a role for homocysteine-related neural damage in Alzheimer's dementia. McCaddon et al. (1998) found that Alzheimer's patients exhibited significantly higher plasma levels of homocysteine than non-demented controls and that, further, neuropsychological status was significantly related both to homocysteine and vitamin $\mathrm{B}_{12}$ levels. This finding has been replicated and extended by other groups (Lehmann et al. 1999), where it has also been found that, in addition to Alzheimer's patients, homocysteine levels are predictive of neuropsychological status in individuals suffering from other forms of dementia.

Although there are a number of published studies which have suggested links with vitamin status and cognitive performance amongst the elderly (for example, see Goodwin et al. 1983; Sommer \& Wolkowitz, 1988; Bell et al. 1990; Riggs et al. 1996), these studies have been correlational in nature and have provided no clear hypothesis as to the mechanisms underlying these relationships. One intervention study, however, revealed no effect of supplementation on cognitive performance (Chome et al. 1986), although this can possibly be interpreted in terms of the low subject numbers and the relatively short period of supplementation (5 weeks). Stronger evidence can be seen in the results of Deijen et al. (1992), who demonstrated significant improvements in cognitive function following vitamin $\mathrm{B}_{6}$ supplementation in a larger sample of healthy, self-supporting men aged between 70 and 79 years. The evidence for a definite role for B-complex vitamins in the cognitive function of the elderly remains, therefore, mostly suggestive (albeit strongly so).

\section{Antioxidant vitamins and cerebrovascular health}

It has also been proposed that cognitive impairment might be prevented or significantly delayed by increased intake of antioxidants in the diet, such as vitamins $\mathrm{C}$ and $\mathrm{E}$ (for example, see Kalmijn et al. 1997; Lethem \& Orrell, 1997). This view is based on various lines of evidence.

Biochemical and physiological studies implicate oxidative damage to the central nervous system microvasculature in the aetiology of neurodegenerative diseases, including Alzheimer's disease (Richardson, 1993; Thomas et al. 1996). At the same time, oxidative modification of LDL is probably a critical component of the atherosclerotic process (Witztum, 1994), and there is a well-established link between the prevalence of dementia and the presence of one or more E4 alleles of the apolipoprotein E gene (Bondi et al. 1995; Rubinsztein, 1997). The apolipoprotein E gene produces apolipoprotein E which is involved in, among other things, transporting cholesterol in the blood and neuronal repair (Rubinsztein, 1997).

More directly, several studies have demonstrated significant relationships between cognitive functioning in the elderly and antioxidant nutrient intake or status. Gale et al. (1996), for example, reported an association between cognitive impairment and both low intake and plasma levels of vitamin $\mathrm{C}$, and also between cognitive impairment and increased risk from 
ischaemic stroke. These authors specifically suggested that vitamin $\mathrm{C}$ status may influence cognitive function in elderly people through an effect on atherogenesis. Another study (Ortega et al. 1997) found significant relationships between cognitive functioning, measured using the Mini Mental State Examination, and some ten dietary-intake variables. Included among these were intakes of vitamin $\mathrm{C}, \beta$-carotene, folate and $\mathrm{Fe}$ (positive associations), and intakes of monounsaturated fatty acids, saturated fatty acids and cholesterol (negative associations). Vitamin E status has also been specifically linked with memory function (Perkins et al. 1999). Conversely, however, Kalmijn et al. (1997) found no significant relationships between intakes of the potential antioxidants vitamins $\mathrm{C}$ and $\mathrm{E}, \beta$-carotene and various flavanoids, and either cognitive impairment or cognitive decline in elderly men, again assessed with the Mini Mental State Examination, which is a measure of overall neuropsychological function. This lack of a relationship between vitamin $\mathrm{E}$ and cognition has also been replicated by Jama et al. (1996).

Of course, without additional information, conclusions cannot be drawn about cause and effect from correlational studies. One published intervention trial, however, revealed significant correlations between vitamin $\mathrm{C}$ levels, mood, performance on measures of memory and attention and global neuropsychological status in elderly individuals after 12 months of supplementation with a range of antioxidant vitamins (Smith et al. 1999b). Clear interpretation of the results of this study is, however, made difficult by two facts. First, the fact that cognitive function did not significantly change over the course of the supplementation period. Second, the reported significant correlations between vitamin status and psychological status were not adjusted for the effect of multiple comparisons and, if this statistically appropriate procedure were carried out, these effects would probably disappear. Nevertheless, there is sufficient evidence to suggest that studies of the effects of antioxidant supplementation may well yield positive outcomes for cognitive functioning (Lethem \& Orrell, 1997). This includes the possible involvement of other mechanisms, such as dietary modification of immune function, whereby, for example, vitamin $\mathrm{E}$ could be expected to influence the development of arteriosclerosis (Meydani et al. 1998). The finding that there is an association between the apolipoprotein E4 genotype and dementia also suggests that potentially protective dietary interventions could be targeted for high-risk groups. Again, this conclusion is speculative.

\section{Summary}

We have reviewed the potential nutritional influences on cognitive function and arousal, excepting severe malnutrition for which substantial literature exists. New developments in understanding dietary influences on neurohormonal systems, and their implications for cognition and affect, allow reinterpretation of both earlier and recent findings.

The methods and outcomes of numerous studies, and inferred mechanisms, are disparate and diverse, so generalisations are difficult. Nevertheless, some cautious predictions can be made; with due allowance for circadian rhythms, acute effects of meals on both cognition and arousal can be observed. Breakfast can improve cognitive function, though not universally, and most evidently in young and nutritionally vulnerable children. The composition of meals may be more influential than meal size or timing, particularly when substantial nutritional variations from habitual meals are encountered. Acutely, carbohydrate-rich-protein-poor meals are more likely to be sedating and anxiolytic, while inducing lapses of sustained attention: by comparison, protein-rich meals may be arousing, enhancing reaction time but also unfocused vigilance. These acute effects may vary with current nutritional state, time of day, and temperament. Chronically, protein-rich diets have been associated with decreased positive and increased 
negative affect relative to carbohydrate-rich diets. Evidence continues to accumulate that these effects may be mediated by diet-induced changes in monoamine neurotransmitter activity, functioning of the hypothalamic pituitary adrenal axis and cortisol secretion.

Fat-rich meals can reduce alertness after a delay, especially where they differ from habitual fat intake. This might be mediated by CCK release. Even so, manipulation of fat intake produced few consistent effects on performance. Effects of pure fat intake may be less disruptive to performance than either pure carbohydrate or protein, perhaps because of relatively benign neurohormonal responses.

It is argued that many of these effects should be interpreted in the context of idiosyncratic response to challenging, often stressful, tests of performance. A case in point is the change in performance after administration of glucose, which may depend on the amount of sympathetic activation, glucocorticoid secretion and pancreatic function, reflecting the glucoregulatory ability of the individual. This argument is supported by recent evidence of astrocytic buffering of changes in cerebral glucose supply, which is susceptible to acute stress. That is, behavioural effects of glucose ingestion should not be seen as resulting from simple fuelling of neural activity.

Thus, the outcomes can often be predicted by vulnerabilities based on individual differences in coping with stressful challenges, interacting with nutritional history. For instance, anxious introverts are less susceptible to a 'post-lunch dip' in performance, as well as being protected from stress-induced deterioration in mood by prior consumption of high-carbohydrate-protein-poor meals. Again, there is evidence that these effects may be mediated by nutritionally sensitive neurohormonal processes. Functioning of such systems may also be susceptible to dietary influences on neural membrane fluidity, such as cholesterol and/or essential fatty acid levels.

Women who diet to lose weight appear vulnerable to cognitive impairment; the evidence suggests that preoccupying thoughts during dieting reduce working memory capacity, impairing performance independently of weight loss.

Finally, the elderly, often nutritionally 'at risk', may be particularly susceptible to dietdependent cognitive decline. There is increasing evidence for a key role for the B-complex vitamins, and vitamins $\mathrm{C}$ and $\mathrm{E}$, particularly in protecting against cognitive impairment resulting from deteriorating cerebrovascular integrity.

Future research should aim to extend this integration of earlier and recent findings, so that the full implications of dietary influences on cognition and arousal can be understood. Then, efficient strategies can be employed that will benefit the nutritional and neuropsychological health of susceptible individuals.

\section{References}

Åberg-Wistedt A, Hasselmark L, Stain-Malmgren R, Apéria B, Kjellman BF \& Mathé AA (1998) Serotonergic 'vulnerability' in affective disorder: a study of the tryptophan depletion test and relationships between peripheral and central serotonin indexes in citalopram-responders. Acta Psychiatrica Scandinavica 97, 374-380.

AHA/Medical Scientific Statement (1997) Guide to primary prevention of cardiovascular diseases. Circulation 95, 2329-2331.

Anderson IM, Parry Billings M, Newsholme EA, Fairburn CG \& Cowen PJ (1990) Dieting reduces plasma tryptophan and alters brain 5-HT function in women. Psychological Medicine 20, 785-791.

Anderson KE, Rosner W, Khan MS, New MI, Pang S, Wissel PS \& Kappas A (1987) Diet-hormone interactions: protein-carbohydrate ratio alters reciprocally the plasma levels of testosterone and cortisol and their respective binding globulins in man. Life Sciences 40, 1761-1768.

Anonymous (1957) Physiologic results of breakfast habits. Nutrition Reviews 15, 196-198.

Azari NP (1991) Effects of glucose on memory processes in young adults. Psychopharmacology 105, 521-524. 
Baddeley AD (1986) Working Memory. Oxford: Oxford University Press.

Bell IR, Edman JS, Miller J, Hebben N, Linn RT, Ray D \& Kayne HL (1990) Relationship of normal serum vitamin B-12 and folate levels to cognitive test performance in subtypes of geriatric major depression. Journal of Geriatric Psychiatry and Neurology 3, 98-105.

Bellisle F, Blundell JE, Dye L, Fantino M, Fern E, Fletcher RJ, Lambert J, Roberfroid MB, Specter S, Westenhöfer J \& Westerterp-Plantenga MS (1998) Functional food science and behaviour and psychological functions. British Journal of Nutrition 80, S173-S193.

Benkelfat C, Ellenbogen MA, Dean P, Palmour RM \& Young SN (1994) Mood-lowering effect of tryptophan depletion. Enhanced susceptibility in young men at genetic risk for major affective disorders. Archives of General Psychiatry 51, 687-697.

Benton D (1990) The impact of increasing blood glucose on psychological functioning. Biological Psychology 30, 13-19.

Benton D (1995) Do low cholesterol levels slow mental processing? Psychosomatic Medicine 57, 50-53.

Benton D, Brett V \& Brain PF (1987) Glucose improves attention and reaction to frustration in children. Biological Psychology 24, 95-100.

Benton D \& Owens DS (1993) Blood glucose and human memory. Biological Psychology 24, 95-100.

Benton D, Owens DS \& Parker PY (1994) Blood glucose influences memory and attention in young adults. Neuropsychologia 32, 595-607.

Benton D \& Sargent J (1992) Breakfast, blood glucose and memory. Biological Psychology 33, 207-210.

Berlin I, Grimaldi A, Landault C, Cesselin F \& Puech AJ (1994) Suspected postprandial hypoglycemia is associated with beta-adrenergic hypersensitivity and emotional distress. Journal of Clinical Endocrinology and Metabolism 79, $1428-1433$.

Biston P, Van Cauter E, Ofek G, Linkowski P, Polonsky KS \& Degaute JP (1996) Diurnal variations in cardiovascular function and glucose regulation in normotensive humans. Hypertension 28, 863-871.

Blair EH, Wing RR \& Wald A (1991) The effect of laboratory stressors on glycemic control and gastrointestinal transit time. Psychosomatic Medicine 53, 133-143.

Bohnen N, Nicolson N, Sulon J \& Jolles J (1991) Coping style, trait anxiety and cortisol reactivity during mental stress. Journal of Psychosomatic Research 35, 141-147.

Bondi MW, Salmon DP \& Monsch AU (1995) Episodic memory changes are associated with the ApoE-epsilon 4 allele in nondemented older adults. Neurology 45, 2203-2206.

Brandenberger G, Follenius M, Wittersheim G, Salame P, Siméoni M \& Reinhardt B (1980) Plasma catecholamines and pituitary adrenal hormones related to mental task demand under quiet and noise conditions. Biological Psychology 10, 239-252.

Buffenstein R, Karklin A \& Driver HS (2000) Beneficial physiological and performance responses to restricted energy intake in healthy overweight women. Physiology and Behavior 68, 439-444.

Carlson AJ (1916) The Control of Hunger in Health and Disease. Chicago: University of Chicago Press.

Channon S, Baker JE \& Robertson MM (1993) Working memory in clinical depression: An experimental study. Psychological Medicine 23, 87-91.

Checkley S (1996) The neuroendocrinology of depression and chronic stress. British Medical Bulletin 52, 597-617.

Chome J, Paul T, Pudel V, Bleyl J, Hesker, H, Huppe R \& Kubleer W (1986) Effects of suboptimal vitamin status on behaviour. Bibliotheca Nutritio et Dieta 38, 94-103.

Christensen L (1993) Effects of eating behavior on mood: A review of the literature. International Journal of Eating Disorders 14, 171-183.

Christensen L \& Redig C (1993) Effect of meal composition on mood. Behavioral Neuroscience 107, $346-353$.

Christie MJ \& McBrearty EM (1979) Psychophysiological investigations of post lunch state in male and female subjects. Ergonomics 22, 307-323.

Clark KB, Naritoku DK, Smith DC, Browning RA \& Jensen RA (1999) Enhanced recognition memory following vagus nerve stimulation in human subjects. Nature Neuroscience 2, 94-98.

Conners CK \& Blouin AG (1983) Nutritional effects on behavior of children. Journal of Psychiatric Research 17, 193-201.

Cowen PJ (1996) The serotonin hypothesis: necessary but not sufficient. In Selective Serotonin Re-uptake Inhibitors: Advances In Basic Research and Clinical Practice, 2nd ed., pp. 63-86 [JP Feighner and WF Boyer, editors]. London: John Wiley.

Cowen PJ, Clifford EM, Walsh AE, Williams C \& Fairburn CG (1996) Moderate dieting causes 5-HT ${ }_{2 \mathrm{C}}$ receptor supersensitivity. Psychological Medicine 26, 1155-1159.

Craft S, Murphy C \& Wemstrom J (1994) Glucose effects on complex memory and nonmemory tasks: the influence of age, sex, and glucoregulatory response. Psychobiology 22, 95-105.

Craig A (1986) Acute effects of meals on perceptual and cognitive efficiency. Nutrition Reviews 44, $163-171$.

Craig A, Baer K \& Diekmann A (1981) The effects of lunch on sensory-perceptual functioning in man. International Archives of Occupational and Environmental Health 49, 105-114.

Craik FM, Anderson ND, Kerr SA \& Li KZH (1995) Memory change in normal ageing. In Handbook of Memory Disorders, pp. 211-241 [AP Baddeley, BA Wilson and FN Watts, editors]. Chichester: Wiley.

Cunliffe A, Obeid OA \& Powell-Tuck J (1997) Post-prandial changes in measures of fatigue: effect of a mixed or a pure carbohydrate or pure fat meal. European Journal of Clinical Nutrition 51, 831-838. 
Dallman MF, Strack AM, Akana SF, Bradbury MJ, Hanson ES, Scribner KA \& Smith M (1993) Feast and famine: critical role of glucocorticoids with insulin in daily energy flow. Frontiers of Neuroendocrinology 14, 303-347.

Darke S (1988) Anxiety and working memory capacity. Cognition and Emotion 2, 145-154.

Dauncey MJ \& Bicknell RJ (1999) Nutrition and neurodevelopment: mechanisms of developmental dysfunction and disease in later life. Nutrition Research Reviews 12, 231-253.

De Castro JM (1987a) Circadian rhythms of the spontaneous meal pattern, macronutrient intake, and mood of humans. Physiology and Behavior 40, 437-446.

De Castro JM (1987b) Macronutrient relationships with meal patterns and mood in the spontaneous feeding behavior of humans. Physiology and Behavior 39, 561-569.

De Feo P, Gallai V, Mazzotta G, Crispino G, Torlone E, Perriello G, Ventura MM, Santeusanio F, Brunetti P \& Bolli GB (1988) Modest decrements in plasma glucose concentration cause early impairment in cognitive function and later activation of glucose counterregulation in the absence of hypoglycemic symptoms in normal man. Journal of Clinical Investigation 82, 436-444.

Deijen JB, Heemstra ML \& Orlebeke JF (1989) Dietary effects on mood and performance. Journal of Psychiatric Research 23, 275-283.

Deijen JB, van der Beek EJ, Orlebeke JF \& van den Berg H (1992) Vitamin B-6 supplementation in elderly men: effects on mood, memory and mental effort. Psychopharmacology 109, 489-496.

De Kloet ER, Oitzl MS \& Joels M (1993) Functional implications of brain corticosteroid receptor diversity. Cellular and Molecular Neurobiology 13, 433-455.

Dickie NH \& Bender AE (1982) Breakfast and performance in school children. British Journal of Nutrition 48, 483-496.

Donohoe RT \& Benton D (1999a) Cognitive functioning is susceptible to the level of blood glucose. Psychopharmacology 145, 378-385.

Donohoe RT \& Benton D (1999b) Declining blood glucose levels after a cognitively demanding task predict subsequent memory. Nutritional Neuroscience 2, 413-424.

Dusek JB, Mergler ML \& Kermis MD (1976) Attention, encoding, and information processing in low- and high-testanxious children. Child Development 47, 201-207.

Dye L, Lluch A \& Blundell JE (2000) Macronutrients and mental performance. Nutrition 16, 1021-1034.

Fernández-Real JM, Ricart W \& Casamitjana R (1997) Lower cortisol levels after oral glucose in subjects with insulin resistance and abdominal obesity. Clinical Endocrinology (Oxford) 47, 583-588.

Fernstrom JD (1983) Role of precursor availability in control of monoamine biosynthesis in brain. Physiological Reviews 63, 484-546.

Fernstrom JD \& Fernstrom MH (1994) Dietary effects on tyrosine availability and catecholamine synthesis in the central nervous system: possible relevance to the control of protein intake. Proceedings of the Nutrition Society 53, 419-429.

Fernstrom MH \& Fernstrom JD (1995) Brain tryptophan concentrations and serotonin synthesis remain responsive to food consumption after the ingestion of sequential meals. American Journal of Clinical Nutrition 61, 312-319.

Fibiger HC (1991) Cholinergic mechanisms in learning, memory and dementia: A review of recent evidence. Trends in Neuroscience 14, 220-223.

Filipini D, Gijsbers K, Birmingham MK, Kraulis I \& Dubrovsky B (1991) Modulation by adrenal steroids of limbic function. Journal of Steroid Biochemistry and Molecular Biology 39, 245-252.

Fillenz M, Lowry JP, Boutelle MG \& Fray AE (1999) The role of astrocytes and noradrenaline in neuronal glucose metabolism. Acta Physiologica Scandinavica 167, 275-284.

Fischer K, Colombani PC, Langhans W \& Wenk C (2001) Cognitive performance and its relationship with postprandial metabolic changes after ingestion of different macronutrients in the morning. British Journal of Nutrition 85, 393-405.

Folkard S \& Monk TH (1985) Hours of Work: Temporal Factors in Work Scheduling. Chichester: Wiley.

Food and Agriculture Organization/World Health Organization (1998) Carbohydrates in Human Nutrition. Report no. 66. Rome: FAO.

Foster JK, Lidder PG \& Sünram SI (1998) Glucose and memory: Fractionation of enhancement effects. Psychopharmacology 137, 259-270.

Foster-Powell K \& Brand Miller J (1995) International Tables of Glycemic Index. American Journal of Clinical Nutrition 62, S871-S890.

Fox CF (1981) Neuropsychological correlates of anorexia nervosa. International Journal of Psychiatry in Medicine 11, $285-290$.

Gale CR, Martyn C \& Cooper C (1996) Cognitive impairment and mortality in a cohort of elderly people. British Medical Journal 312, 608-611.

Gallerani M, Manfredini R, Caracciolo S, Scapoli C, Molinari S \& Fersini C (1995) Serum cholesterol concentrations in parasuicide. British Medical Journal 310, 1632-1634.

Gibson EL, Checkley S, Papadopoulos A, Poon L, Daley S \& Wardle J (1999) Increased salivary cortisol reliably induced by a protein-rich midday meal. Psychosomatic Medicine 61, 214-224.

Gibson EL, Sivapathasundaram V \& Judd PA (2000) Learnt protein appetite in rats and human beings: role of the hypothalamic pituitary adrenal axis. Appetite 35, 288.

Glueck CJ, Tieger M, Kunkel R, Hamer T, Tracy T \& Speirs J (1994) Hypocholesterolemia and affective disorders. American Journal of Medical Science 308, 218-225. 
Gold PE (1986) Glucose modulation of memory storage processing. Behavioral and Neural Biology 45, 342-349.

Gold PE (1995) Role of glucose in regulating the brain and cognition. American Journal of Clinical Nutrition 61, 987S-995S.

Goodwin GM, Fairburn CG \& Cowen PJ (1987) Dieting changes serotonergic function in women, not men: implications for the aetiology of anorexia nervosa? Psychological Medicine 17, 839-842.

Goodwin JS, Goodwin JM \& Garry PJ (1983) Association between nutritional status and cognitive functioning in a healthy elderly population. Journal of the American Medical Association 249, 2917-2921.

Green MW, Elliman NA \& Rogers PJ (1995) Lack of effect of short-term fasting on cognitive function. Journal of Psychiatric Research 29, 245-253.

Green MW, Elliman NA \& Rogers PJ (1997a) The effects of food deprivation and incentive motivation on blood glucose levels and cognitive function. Psychopharmacology 134, 88-94.

Green MW, Elliman NA \& Rogers PJ (1997b) Impaired cognitive performance in dieters: Failure of attentional focus or resource capacity limitation. British Journal of Health Psychology 2, 259-267.

Green MW \& Rogers PJ (1993) Selective attention to food and body shape words in dieters and restrained nondieters. International Journal of Eating Disorders 14, 515-517.

Green MW \& Rogers PJ (1995) Impaired cognitive function during spontaneous dieting. Psychological Medicine 25, 1003-1010.

Green MW \& Rogers PJ (1998) Impairments in working memory associated with spontaneous dieting behaviour. Psychological Medicine 28, 1063-1070.

Green MW, Rogers PJ, Elliman NA \& Gatenby SJ (1994) Impairment of cognitive function associated with dieting and high levels of dietary restraint. Physiology and Behavior 55, 447-452.

Green MW, Taylor MA, Elliman NA \& Rhodes O (2001) Placebo expectancy effects in the relationship between glucose and cognition. British Journal of Nutrition 86, 173-179.

Gregory J, Foster K, Tyler H \& Wiseman M (1990) The Dietary and Nutritional Survey of British Adults. London: Her Majesty's Stationery Office.

Grimes MA, Cameron JL \& Fernstrom JD (2000) Cerebrospinal fluid concentrations of tryptophan and 5-hydroxyindoleacetic acid in Macaca mulatta: diurnal variations and response to chronic changes in dietary protein intake. Neurochemical Research 25, 413-422.

Hagström-Toft E, Arner P, Wahrenberg H, Wennlund A, Ungerstedt U \& Bolinder J (1993) Adrenergic regulation of human adipose tissue metabolism in situ during mental stress. Journal of Clinical Endocrinology and Metabolism 76, 392-398.

Hall JL, Gonder-Frederick LA, Chewning WW, Silveira J \& Gold PE (1989) Glucose enhancement of performance on memory tests in young and aged humans. Neuropsychologia 27, 1129-1138.

Hart KE \& Chiovari P (1988) Inhibition of eating behavior: negative cognitive effects of dieting. Journal of Clinical Psychology 54, 427-430.

Heninger GR, Delgado PL \& Charney DS (1996) The revised monoamine theory of depression: a modulatory role for monoamines, based on new findings from monoamine depletion experiments in humans. Pharmacopsychiatry 29, $2-11$.

Herman CP \& Polivy J (1980) Restrained eating. In Obesity, pp. 208-225 [AJ Stunkard, editor]. Philadelphia: WB Saunders.

Heron DS, Shinitzsky M, Hershkowitz M \& Samuel D (1980) Lipid fluidity markedly modulates the binding of serotonin to mouse brain membranes. Proceedings of the National Academy of Sciences USA 77, 7463-7467.

Hibbeln JR, Linnoila M, Umhau JC, Rawlings R, George DT \& Salem N Jr (1998) Essential fatty acids predict metabolites of serotonin and dopamine in cerebrospinal fluid among healthy control subjects, and early- and late-onset alcoholics. Biological Psychiatry 44, 235-242.

Hill AJ, Weaver CFL \& Blundell JE (1991) Food craving, dietary restraint and mood. Appetite 17, 187-197.

Horner HC, Packan DR \& Sapolsky RM (1990) Glucocorticoids inhibit glucose transport in cultured hippocampal neurons and glia. Neuroendocrinology 52, 57-64.

Huether GE (1988) Amino Acid Availability and Brain Function in Health and Disease. Berlin: Springer.

Huether G, Schmidt S \& Rüther E (1998) Nutritional effects on central serotonergic activity: a hypothesis on the unconscious self-manipulation of mood by food intake and dietary selection. Nutritional Neuroscience 1, 3-7.

Hutchinson RC (1952) Meal habits and their effects on performance. Nutrition Abstracts and Reviews 22, $25-33$.

Ide K, Schmalbruch IK, Quistorff B, Horn A \& Secher NH (2000) Lactate, glucose and $\mathrm{O}_{2}$ uptake in human brain during recovery from maximal exercise. Journal of Physiology 522, Part 1, 159-164.

Jama JW, Launer LJ, Witteman JCM, Denbreeijen JH, Breteler MMB, Grobbee DE \& Hofman A (1996) Dietary antioxidants and cognitive function in a population-based sample of older persons: The Rotterdam Study. American Journal of Epidemiology 122, 275-280.

Jewett ME, Wyatt JK, Ritz-De Cecco A, Khalsa SB, Dijk DJ \& Czeisler CA (1999) Time course of sleep inertia dissipation in human performance and alertness. Journal of Sleep Research 8, 1-8.

Kalmijn S, Feskens EJM, Launer LJ \& Kromhout D (1997) Polyunsaturated fatty acids, antioxidants and cognitive function in very old men. American Journal of Epidemiology 145, 33-41.

Kanarek RB \& Swinney D (1990) Effects of food snacks on cognitive performance in male college students. Appetite 14, 15-27.

Kaplan JR, Manuck SB, Fontenot MB, Muldoon MF, Shively CA \& Mann JJ (1997) The cholesterol-serotonin hypothesis: 
Interrelationships among dietary lipids, central serotonergic activity and social behavior in monkeys. In Lipids, Health and Behavior, pp. 139-165 [M Hillbrand and RT Spitz, editors]. Washington, DC: American Psychological Association.

Kaplan RJ, Greenwood CE, Winocur G \& Wolever TM (2000) Cognitive performance is associated with glucose regulation in healthy elderly persons and can be enhanced with glucose and dietary carbohydrates. American Journal of Clinical Nutrition 72, 825-836.

Keith RE, O'Keeffe KA, Blessing DL \& Wilson GD (1991) Alterations in dietary carbohydrate, protein, and fat intake and mood state in trained female cyclists. Medicine and Science in Sports and Exercise 23, 212-216.

Kelly TH, Foltin RW, Rolls BJ \& Fischman MW (1994) Effect of meal macronutrient and energy content on human performance. Appetite 23, 97-111.

Kennedy DO \& Scholey AB (2000) Glucose administration, heart rate and cognitive performance: effects of increasing mental effort. Psychopharmacology 149, 63-71.

Kingston K, Szmukler G, Andrewes D, Tress B \& Desmond P (1996) Neuropsychological and structural brain changes in anorexia nervosa before and after refeeding. Psychological Medicine 26, 15-28.

Kirschbaum C, Bono EG, Rohleder N, Gessner C, Pirke KM, Salvador A \& Hellhammer DH (1997) Effects of fasting and glucose load on free cortisol responses to stress and nicotine. Journal of Clinical Endocrinology and Metabolism 82, 1101-1105.

Kirschbaum C, Wolf OT, May M, Wippich W \& Hellhammer DH (1996) Stress- and treatment-induced elevations of cortisol levels associated with impaired declarative memory in healthy adults. Life Sciences 58, 1475-1483.

Kleinman RE, Murphy JM, Little M, Pagano M, Wehler CA, Regal K \& Jellinek MS (1998) Hunger in children in the United States: potential behavioral and emotional correlates. Pediatrics 101, E3.

Koehler KM, Romero LJ, Stauber PM, Pareotubbeh SL, Liang HC, Baumgartner RN, Garry PJ, Allen RH \& Stabler SP (1996) Vitamin supplementation and other variables affecting serum homocysteine and methylmalonic acid concentrations in elderly men and women. Journal of the American College of Nutrition 15, 363-376.

Korol DL \& Gold PE (1998) Glucose, memory, and aging. American Journal of Clinical Nutrition 67, 764S-771S.

Kretchmer N, Beard JL \& Carlson S (1996) The role of nutrition in the development of normal cognition. American Journal of Clinical Nutrition 63, 997S-1001S.

Kretsch MJ, Fong AKH, Green MW \& Johnson HL (1998) Cognitive function, iron status and haemoglobin concentration in obese dieting women. European Journal of Clinical Nutrition 52, 512-518.

Kretsch MJ, Green MW, Fong AKH, Elliman NA \& Johnson HL (1997) Cognitive effects of a long-term, weight reducing diet. International Journal of Obesity 21, 14-21.

Laessle RG, Platte P, Schweiger U \& Pirke KM (1996) Biological and psychological correlates of intermittent dieting behavior in young women. A model for bulimia nervosa. Physiology and Behavior 60, 1-5.

Lapp JE (1981) Effects of glycemic alterations and noun imagery on the learning of paired associates. Journal of Learning Disabilities 14, 35-38.

Lehmann M, Gottfries CG \& Regland B (1999) Identification of cognitive impairment in the elderly: Homocysteine is an early marker. Dementia and Geriatric Cognitive Disorders 10, 12-20.

Lethem R \& Orrell M (1997) Antioxidants and dementia. Lancet 349, 1189-1190.

Lieberman HR, Corkin S, Spring BJ, Growdon JH \& Wurtman RJ (1983) Mood, performance, and pain sensitivity: changes induced by food constituents. Journal of Psychiatric Research 17, 135-145.

Lieberman HR, Spring BJ \& Garfield GS (1986) The behavioral effects of food constituents: strategies used in studies of amino acids, protein, carbohydrate and caffeine. Nutrition Reviews 44, Suppl., 61-70.

Lindenbaum J, Healton EB, Savage DG, Brust JC, Garrett TJ, Podell ER, Marcel PD, Stabler SP \& Allen RH (1988) Neuropsychiatric disorders caused by cobalamin deficiency in the absence of anemia or macrocytosis. The New England Journal of Medicine 318, 1720-1728.

Lipsitz LA, Ryan SM, Parker JA, Freeman R, Wei JY \& Goldberger AL (1993) Hemodynamic and autonomic nervous system responses to mixed meal ingestion in healthy young and old subjects and dysautonomic patients with postprandial hypotension. Circulation 87, 391-400.

Lloyd HM, Green MW \& Rogers PJ (1994) Mood and cognitive performance effects of isocaloric lunches differing in fat and carbohydrate content. Physiology and Behavior 56, 51-57.

Lloyd HM, Rogers PJ, Hedderley DI \& Walker AF (1996) Acute effects on mood and cognitive performance of breakfasts differing in fat and carbohydrate content. Appetite 27, 151-164.

Lowe MR (1993) The effects of dieting on eating behaviour: A three factor model. Psychological Bulletin 114, $100-121$.

Lupien SJ, Gillin CJ \& Hauger RL (1999) Working memory is more sensitive than declarative memory to the acute effects of corticosteroids: a dose-response study in humans. Behavioral Neuroscience 113, 420-430.

Lussier-Cacan S, Xhingnesse M, Piolot A, Selhub J, Davignon J \& Genest J (1996) Plasma total homocysteine in healthy subjects: Sex specific relation with biological traits. American Journal of Clinical Nutrition 64, 587-593.

Lyons PM \& Truswell AS (1988) Serotonin precursor influenced by type of carbohydrate meal in healthy adults. American Journal of Clinical Nutrition 47, 433-439.

McCaddon A, Davies G, Hudson P, Tandy S \& Cattell H (1998) Total serum homocysteine in senile dementia of the Alzheimer type. International Journal of Geriatric Psychiatry 13, 235-239.

McGaugh JL (1989) Involvement of hormonal and neuromodulatory systems in the regulation of memory storage. Annual Review of Neuroscience 12, 255-287.

Macht M (1996) Effects of high- and low-energy meals on hunger, physiological processes and reactions to emotional stress. Appetite 26, 71-88. 
McMahon M, Gerich J \& Rizza R (1988) Effects of glucocorticoids on carbohydrate metabolism. Diabetes/Metabolism Reviews 4, 17-30.

McMurchie EJ \& Patten GS (1988) Dietary cholesterol influences cardiac $\beta$-adrenergic receptor adenylate cyclase activity in the marmoset monkey by changes in membrane cholesterol status. Biochimica et Biophysica Acta $\mathbf{9 4 2}$, 324-332.

Manning CA, Hall JL \& Gold PE (1990) Glucose effects on memory and other neuropsychological tests in elderly humans. Psychological Science 1, 307-311.

Manning CA, Parsons MW \& Cotter EM (1997) Glucose effects on declarative and non-declarative memory in healthy elderly and young adults. Psychobiology 25, 103-108.

Manning CA, Ragozzino ME \& Gold PE (1993) Glucose enhancement of memory in patients with probable senile dementia of the Alzheimer's type. Neurobiology of Aging 14, 523-528.

Maran A, Cranston I, Lomas J, Macdonald I \& Amiel SA (1994) Protection by lactate of cerebral function during hypoglycaemia. Lancet 343, 16-20.

Marks V \& Teale JD (1993) Hypoglycaemia in the adult. Ballieres Clinical Endocrinology and Metabolism 7, 705-729.

Markus CR, Olivier B, Panhuysen GEM, Van der Gugten J, Alles MS, Tuiten A, Westenberg HGM, Fekkes D, Kopeschaar HF \& de Haan EEHF (2000a) The bovine protein alpha-lactalbumin increases the plasma ratio of tryptophan to the other large neutral amino acids, and in vulnerable subjects raises brain serotonin activity, reduces cortisol concentration, and improves mood under stress. American Journal of Clinical Nutrition 71, 1536-1544.

Markus CR, Panhuysen G, Jonkman LM \& Bachman M (1999) Carbohydrate intake improves cognitive performance of stress-prone individuals under controllable laboratory stress. British Journal of Nutrition 82, 457-467.

Markus CR, Panhuysen G, Tuiten A, Koppeschaar H, Fekkes D \& Peters ML (1998) Does carbohydrate-rich, proteinpoor food prevent a deterioration of mood and cognitive performance of stress-prone subjects when subjected to a stressful task? Appetite 31, 49-65.

Markus R, Panhuysen G, Tuiten A \& Koppeschaar H (2000b) Effects of food on cortisol and mood in vulnerable subjects under controllable and uncontrollable stress. Physiology and Behavior 70, 333-342.

Martin PY \& Benton D (1999) The influence of a glucose drink on a demanding working memory task. Physiology and Behavior 67, 69-74.

Mathias CJ (1990) Effect of food intake on cardiovascular control in patients with impaired autonomic function. Journal of Neuroscience Methods 34, 193-200.

Melanson KJ, Westerterp-Plantenga MS, Campfield LA \& Saris WH (1999) Blood glucose and meal patterns in timeblinded males, after aspartame, carbohydrate, and fat consumption, in relation to sweetness perception. British Journal of Nutrition 82, 437-446.

Messier C \& Gagnon M (1996) Glucose regulation and cognitive functions: relation to Alzheimer's disease and diabetes. Behavioural Brain Research 75, 1-11.

Messier C, Gagnon M \& Knott V (1997) Effect of glucose and peripheral glucose regulation on memory in the elderly. Neurobiology of Aging 18, 297-304.

Meydani M, Lipman RD, Han SN, Wu D, Beharka A, Martin KR, Bronson R, Cao G, Smith D \& Meydani SD (1998) The effect of long-term dietary supplementation with antioxidants. Towards Prolongation of the Healthy Life Span 854, 352-360.

Michaud C, Musse N, Nicolas JP \& MeJean L (1991) Effects of breakfast-size on short-term memory, concentration, mood and blood glucose. Journal of Adolescent Health 12, 53-57.

Muldoon MF, Barger SD, Ryan CM, Flory JD, Lehoczky JP, Matthews KA \& Manuck SB (2000) Effects of lovastatin on cognitive function and psychological well-being. American Journal of Medicine 108, 538-547.

Muldoon MF, Ryan CM, Matthews KA \& Manuck SB (1997) Serum cholesterol and intellectual performance. Psychosomatic Medicine 59, 382-387.

Nederkoorn C, Smulders FT \& Jansen A (2000) Cephalic phase responses, craving and food intake in normal subjects. Appetite 35, 45-55.

Newcomer JW, Craft S, Hershey T, Askins K \& Bardgett ME (1994) Glucocorticoid-induced impairment in declarative memory performance in adult humans. Journal of Neuroscience 14, 2047-2053.

Nielson KA \& Jensen RA (1994) Beta-adrenergic receptor antagonist antihypertensive medications impair arousalinduced modulation of working memory in elderly humans. Behavioral and Neural Biology 62, 190-200.

Ogden, J. (1992) Fat Chance: The Myth of Dieting Explained. London: Routledge.

Ortega RM, Requejo AM, Andres P, Lopez-Sobaler AM, Quintas ME, Redondo MR, Navia B \& Rivas T (1997) Dietary intake and cognitive function in a group of elderly people. American Journal of Clinical Nutrition 66, 803-809.

Owens DS, Macdonald I, Benton D, Sytnik N, Tucker P \& Folkard S (1996) A preliminary investigation into individual differences in the circadian variation of meal tolerance: effects on mood and hunger. Chronobiology International 13, 435-447.

Owens DS, Macdonald I, Tucker P, Sytnik N, Totterdell P, Minors D, Waterhouse J \& Folkard S (2000) Diurnal variations in the mood and performance of highly practised young women living under strictly controlled conditions. British Journal of Psychology 91, 41-60.

Palardy J, Havrankova J, Lepage R, Matte R, Belanger R, D’Amour P \& Marie LG (1989) Blood glucose measurements during symptomatic episodes in patients with suspected postprandial hypoglycemia. New England Journal of Medicine 321, 1421-1425. 
Park SB, Coull JT, McShane RH, Young AH, Sahakian BJ, Robbins TW \& Cowen PJ (1994) Tryptophan depletion in normal volunteers produces selective impairments in learning and memory. Neuropharmacology 33, 575-588.

Parker PY \& Benton D (1995) Blood glucose levels selectively influence memory for word lists dichotically presented to the right ear. Neuropsychologia 33, 843-854.

Parsons MW \& Gold PE (1992) Glucose enhancement of memory in elderly humans: An inverted U-dose response curve. Neurobiological Aging 13, 401-404.

Perkins AJ, Hendrie HC, Callahan CM, Gau SJ, Unverzagt FW, Xu Y, Hall KS \& Hui SL (1999) Association of antioxidants with memory in a multiethnic elderly sample using the Third National Health and Nutrition Examination Survey. American Journal of Epidemiology 150, 37-44.

Phillips WT, Tilson KS \& Schwartz JG (1996) Use of a physiologic oral glucose solution for screening for impaired glucose tolerance and non-insulin-dependent diabetes mellitus. Archives of Pathology and Laboratory Medicine 120, 842-846.

Pollitt E, Jacoby E \& Cueto S (1996) School breakfast and cognition among nutritionally at-risk children in the Peruvian Andes. Nutrition Reviews 54, S22-S26.

Pollitt E, Leibel RL \& Greenfield D (1981) Brief fasting, stress, and cognition in children. American Journal of Clinical Nutrition 34, 1526-1533.

Pollitt E, Lewis NL, Garza C \& Shulman RJ (1983) Fasting and cognitive function. Journal of Psychiatric Research 17, 169-174.

Pollitt E \& Mathews R (1998) Breakfast and cognition: an integrative summary. American Journal of Clinical Nutrition 67, 804S-813S

Pruessner JC, Gaab J, Hellhammer DH, Lintz D, Schommer N \& Kirschbaum C (1997) Increasing correlations between personality traits and cortisol stress responses obtained by data aggregation. Psychoneuroendocrinology 22, 615-625.

Ransom BR \& Fern R (1997) Does astrocytic glycogen benefit axon function and survival in CNS white matter during glucose deprivation? Glia 21, 134-141.

Reid M \& Hammersley R (1999) The effects of carbohydrates on arousal. Nutrition Research Reviews 12, 3-23.

Rennie MJ (2000) When having the nerve is helped by having the muscle. Journal of Physiology 522, 1.

Richards MMK (1972) Studies of breakfast and mental performance. Nutrition 26, 219-223.

Richardson JS (1993) Free radicals in the genesis of Alzheimer's disease. Annals of the New York Academy of Sciences 696, 73-76.

Riedel WJ, Klaassen T, Deutz NE, van Someren A \& Van Praag HM (1999) Tryptophan depletion in normal volunteers produces selective impairment in memory consolidation. Psychopharmacology (Berl) 141, 362-369.

Riggs KM, Spiro A, Tucker K \& Rush D (1996) Relations of vitamin B-12, vitamin B-6, folate and homocysteine to cognitive performance in the Normative Aging Study. American Journal of Clinical Nutrition 63, 306-314.

Rinn RE (1988) Mental decline in normal ageing. Journal of Geriatric Psychiatry and Neurology 1, 144-158.

Rogers PJ (1995) Food, mood and appetite. Nutrition Research Reviews 8, 243-269.

Rogers PJ \& Green MW (1993) Dieting, dietary restraint and cognitive performance. British Journal of Clinical Psychology 32, 113-116.

Rogers PJ \& Lloyd HM (1994) Nutrition and mental performance. Proceedings of the Nutrition Society 53, $443-456$.

Rosenberg IH \& Miller JW (1992) Nutritional factors in physical and cognitive functions of elderly people. American Journal of Clinical Nutrition 55, 1237S-1243S.

Rosmond R \& Björntorp P (2000) Occupational status, cortisol secretory pattern, and visceral obesity in middle-aged men. Obesity Research 8, 445-450.

Rubinsztein DC (1997) A review of the contribution of apo E genotypes to Alzheimer's disease risk and meta-analysis of apo E associations with other neuro-psychiatric disorders. Nutrition Metabolism and Cardiovascular Diseases $\mathbf{7}$, 267-275.

Scholey AB, Moss MC \& Wesnes K (1998) Oxygen and cognitive performance: the temporal relationship between hyperoxia and enhanced memory. Psychopharmacology 140, 123-126.

Schweiger U, Laessle R, Kittl S, Dickhaut B, Schweiger M \& Pirke KM (1986a) Macronutrient intake, plasma large neutral amino acids and mood during weight-reducing diets. Journal of Neural Transmission 67, 77-86.

Schweiger U, Warnhoff M, Pahl J \& Pirke KM (1986b) Effects of carbohydrate and protein meals on plasma large neutral amino acids, glucose, and insulin plasma levels of anorectic patients. Metabolism 35, 938-943.

Schwizer W, Asal K, Kreiss C, Mettraux C, Borovicka J, Remy B, Guzelhan C, Hartmann D \& Fried M (1997) Role of lipase in the regulation of upper gastrointestinal function in humans. American Journal of Physiology 273, 612-620.

Selhub J, Jaques PF, Wilson PWF, Rush D \& Rosenberg IH (1993) Vitamin status and intake as primary determinants of homocysteinemia in an elderly population. Journal of the American Medical Association 270, $2693-2698$.

Service FJ (1999) Classification of hypoglycemic disorders. Endocrinology and Metabolism Clinics of North America 28, 501-517.

Shapiro ET, Polonsky KS, Copinschi G, Bosson D, Tillil H, Blackman J, Lewis G \& Van Cauter E (1991) Nocturnal elevation of glucose levels during fasting in noninsulin-dependent diabetes. Journal of Clinical Endocrinology and Metabolism 72, 444-454.

Sherwin RS \& Saccà L (1984) Effect of epinephrine on glucose metabolism in humans: contribution of the liver. American Journal of Physiology 247, E157-E165.

Shuford EH Jr (1959) Palatability and osmotic pressure of glucose and sucrose solutions as determinants of intake. Journal of Comparative and Physiological Psychology 52, 150-153. 
Shukhitt-Hale B, Askew EW \& Lieberman HR (1997) Effects of 30 days of undernutrition on reaction time, moods and symptoms. Physiology and Behavior 62, 783-789.

Sieber FE \& Traystman RJ (1992) Special issues: Glucose and the brain. Critical Care Medicine 20, $104-114$.

Smith AP (1985) Diurnal variation in test anxiety and effort. In Advances in Test Anxiety Research, pp. 159-165 [H van der Ploeg, R Schwarzer and C Spielberger, editors]. Lisse: Swets and Zeitlinger.

Smith AP (1992) Time of day and performance. In Handbook of Human Performance, vol. 2, Health and Performance, pp. 217-235 [AP Smith and DM Jones, editors]. London: Academic Press.

Smith AP, Clark R \& Gallagher J (1999a) Breakfast cereal and caffeinated coffee: effects on working memory, attention, mood, and cardiovascular function. Physiology and Behavior 67, 9-17.

Smith AP, Clark RE, Nutt DJ \& Haller JG (1999b) Vitamin C, mood and cognitive functioning in the elderly. Nutritional Neuroscience 2, 249-256.

Smith AP, Kendrick A, Maben A \& Salmon J (1994a) Effects of fat content, weight, and acceptability of the meal on postlunch changes in mood, performance, and cardiovascular function. Physiology and Behavior 55, 417-422.

Smith AP, Kendrick A, Maben A \& Salmon J (1994b) Effects of breakfast and caffeine on cognitive performance, mood and cardiovascular functioning. Appetite 22, 39-55.

Smith AP \& Kendrick AM (1992) Meals and performance. In Handbook of Human Performance, vol. 2, Health and Performance, pp. 1-23 [AP Smith and DM Jones, editors]. London: Academic Press.

Smith AP, Leekham S, Ralph A \& McNeill G (1988) The influence of meal composition on post-lunch performance efficiency and mood. Appetite 10, 195-203.

Smith AP, Maben A \& Brockman P (1994c) Effects of evening meals and caffeine on cognitive performance, mood and cardiovascular functioning. Appetite 22, 57-65.

Smith AP \& Miles C (1986a) Acute effects of meals, noise and nightwork. British Journal of Psychology 77, $377-387$.

Smith AP \& Miles C (1986b) Effects of lunch on selective and sustained attention. Neuropsychobiology 16, 117-120.

Smith AP, Ralph A \& McNeill G (1991) Influence of meal size on postlunch changes in performance efficiency, mood and cardiovascular function. Appetite 16, 85-91.

Smoller JW, Wadden TA \& Stunkard AJ (1987) Dieting and depression: A critical review. Journal of Psychosomatic Research 31, 429-440.

Snorgaard O \& Binder C (1990) Monitoring of blood glucose concentration in subjects with hypoglycaemic symptoms during everyday life. British Medical Journal 300, 16-18.

Snorgaard O, Lassen LH, Rosenfalck AM \& Binder C (1991) Glycaemic thresholds for hypoglycaemic symptoms, impairment of cognitive function, and release of counterregulatory hormones in subjects with functional hypoglycaemia. Journal of Internal Medicine 229, 343-350.

Sommer BR \& Wolkowitz OM (1988) RBC folic acid levels and cognitive performance in elderly patients: A preliminary report. Biological Psychiatry 24, 352-354.

Spoont MR (1992) Modulatory role of serotonin in neural information processing: implications for human psychopathology. Psychological Bulletin 112, 330-350.

Spring B, Maller O, Wurtman J, Digman L \& Cozolino L (1983) Effects of protein and carbohydrate meals on mood and performance: Interactions with sex and age. Journal of Psychiatric Research 17, 155-167.

Stacher G (1985) Satiety effects of cholecystokinin and ceruletide in lean and obese man. Annals of the New York Academy of Sciences 448, 431-436.

Stancampiano R, Melis F, Sarais L, Cocco S, Cugusi C \& Fadda F (1997) Acute administration of a tryptophan-free amino acid mixture decreases 5-HT release in rat hippocampus in vivo. American Journal of Physiology 272, R991-R994.

Sternberg RJ (1986) Advances in the Psychology of Human Intelligence. Hillsdale, NJ: Lawrence Earlbaum.

Strandberg TE, Valvanne J \& Tilvis RS (1993) Serum lipids and depression. Lancet 339, 1001-1002.

Sundell IB, Hallmans G, Nilsson TK \& Nygren C (1989) Plasma glucose and insulin, urinary catecholamines and cortisol responses to test breakfasts with high and low fibre content: the importance of the previous diet. Annals of Nutrition and Metabolism 33, 333-340.

Teff KL (1996) Physiological effects of flavour perception. Trends in Food Science and Technology 7, 448-452.

Teff KL, Young SN \& Blundell JE (1989) The effect of protein or carbohydrate breakfasts on subsequent plasma amino acid levels, satiety and nutrient selection in normal males. Pharmacology Biochemistry and Behavior 34, 829-837.

Tepper BJ, Trail AC \& Shaffer SE (1996) Diet and physical activity in restrained eaters. Appetite 27, 51-64.

Thomas T, Thomas G, McLendon C, Sutton T \& Mullan M (1996) Beta-amyloid mediated vasoactivity and vascular endothelial damage. Nature 380, 168-171.

Tiggemann M (1994) Dietary restraint as a predictor of reported weight loss and affect. Psychological Reports 75, 1679-1682.

Todd RD \& Botteron KN (2001) Is attention-deficit/hyperactivity disorder an energy deficiency syndrome? Biological Psychiatry 50, 151-158.

Ueland PM \& Refsum H (1989) Plasma homocysteine: A risk factor for vascular disease: Plasma levels in health, disease and drug therapy. Journal of Laboratory Clinical Medicine 114, 472-501.

Uvnas-Moberg K, Arn I, Jonsson CO, Ek S \& Nilsonne A (1993) The relationships between personality traits and plasma gastrin, cholecystokinin, somatostatin, insulin, and oxytocin levels in healthy women. Journal of Psychosomatic Research 37, 581-588.

Van Cauter E, Shapiro ET, Tillil H \& Polonsky KS (1992) Circadian modulation of glucose and insulin responses to meals: relationship to cortisol rhythm. American Journal of Physiology 262, E467-E475. 
Van Praag HM (1996) Faulty cortisol/serotonin interplay. Psychopathological and biological characterisation of a new, hypothetical depression subtype (SeCA depression) Psychiatry Research 65, 143-157.

Vaz M, Turner A, Kingwell B, Chin J, Koff E, Cox H, Jennings G \& Esler M (1995) Postprandial sympatho-adrenal activity: its relation to metabolic and cardiovascular events and to changes in meal frequency. Clinical Science 89, 349-357.

Walsh AES, Oldman AD, Franklin M, Fairburn CG \& Cowen PJ (1995) Dieting decreases plasma tryptophan and increases the prolactin response to d-fenfluramine in women but not men. Journal of Affective Disorders 33, 89-97.

Wardle J, Rogers PJ, Judd P, Taylor MA, Rapoport L, Green MW \& Nicholson Perry KN (2000) Randomized trial of the effects of cholesterol-lowering dietary treatment on psychological function. American Journal of Medicine 108, 547-553.

Warren C \& Cooper PJ (1988) Psychological effects of dieting. British Journal of Clinical Psychology 27, 269-270.

Wells AS \& Read NW (1996) Influences of fat, energy, and time of day on mood and performance. Physiology and Behavior 59, 1069-1076.

Wells AS, Read NW \& Craig A (1995) Influences of dietary and intraduodenal lipid on alertness, mood, and sustained concentration. British Journal of Nutrition 74, 115-123.

Wells AS, Read NW \& Macdonald IA (1998) Effects of carbohydrate and lipid on resting energy expenditure, heart rate, sleepiness, and mood. Physiology and Behavior 63, 621-628.

Wells AS, Read NW, Uvnas-Moberg K \& Alster P (1997) Influences of fat and carbohydrate on postprandial sleepiness, mood, and hormones. Physiology and Behavior 61, 679-686.

Widmaier EP (1991) Endocrine control of glucose homeostasis in mammals: food for thought. Molecular and Cellular Endocrinology 75, C1-C6.

Winder R \& Borrill J (1998) Fuels for memory: the role of oxygen and glucose in memory enhancement. Psychopharmacology 136, 349-356.

Wing RR, Blair EH, Epstein LH \& McDermott MD (1990) Psychological stress and glucose metabolism in obese and normal-weight subjects: a possible mechanism for differences in stress-induced eating. Health Psychology 9 , 693-700.

Wing RR, Epstein LH, Blair E \& Nowalk MP (1985) Psychologic stress and blood glucose levels in nondiabetic subjects. Psychosomatic Medicine 47, 558-564.

Wing RR, Vazquez JA \& Ryan CM (1995) Cognitive effects of ketogenic weight reducing diets. International Journal of Obesity 19, 811-816.

Witztum JL (1994) The oxidation hypothesis of atherosclerosis. Lancet 344, 793-795.

Wolever TMS, Jenkins DJA \& Anderson GH (1988) Metabolic response to test meals containing different carbohydrate foods: 2. Plasma amino acid responses and amino acid ratios. Nutrition Research 8, 583-592.

Wolfe BE, Metzger ED \& Stollar C (1997) The effects of dieting on plasma tryptophan concentration and food intake in healthy women. Physiology and Behavior 61, 537-541.

Woods SC (1991) The eating paradox: how we tolerate food. Psychological Reviews 98, 488-505.

Woods SC \& Strubbe JH (1994) The psychobiology of meals. Psychonomic Bulletin and Review 1, 141-155.

Woodside JV, Yarnell JWG, McMaster D, Young IS, Harmon DL, McCrum EE, Patterson CC, Grey KF, Whitehead AS \& Evans A (1998) Effect of B-group vitamins and antioxidant vitamins on hyperhomocysteinemia: a double-blind, randomized, factorial design, controlled trial. American Journal of Clinical Nutrition 67, 858-866.

Wright IK, Upton N \& Marsden CA (1992) Effect of established and putative anxiolytics on extracellular 5-HT and 5HIAA in the ventral hippocampus of rats during behaviour on the elevated X-maze. Psychopharmacology 109, 338-346.

Wurtman RJ, Hefti F \& Melamed E (1981) Precursor control of neurotransmitter synthesis. Pharmacological Reviews 32, 315-335.

Wyon DP, Abrahamsson L, Jartelius M \& Fletcher RJ (1997) An experimental study of the effects of energy intake at breakfast on the test performance of 10-year-old children in school. International Journal of Food Science and Nutrition 48, 5-12.

Yamada F, Inoue S, Saitoh T, Tanaka K, Satoh S \& Takamura Y (1993) Glucoregulatory hormones in the immobilization stress-induced increase of plasma glucose in fasted and fed rats. Endocrinology 132, 2199-2205.

Yokogoshi H \& Wurtman RJ (1986) Meal composition and plasma amino acid ratios: effect of various proteins or carbohydrates, and of various protein concentrations. Metabolism 35, 837-842.

Youdim KA, Martin A \& Joseph JA (2000) Essential fatty acids and the brain: possible health implications. International Journal of Developmental Neuroscience 18, 383-399.

Young JB \& Landsberg L (1977) Stimulation of the sympathetic nervous system during sucrose feeding. Nature 269, 615-617. 